\title{
DAMAGE DETECTION FOR UHPFRC COMMUNICATION TOWER BASED ON FREQUENCY DATA AND PARTICLE SWARM OPTIMIZATION
}

\author{
Sarah JABBAR ${ }^{1}$, Farzad HEJAZI ${ }^{1}$, Ammar N. HANOON², Rizal S. M. RASHID ${ }^{1}$ \\ ${ }^{1}$ Department of Civil Engineering, University Putra Malaysia, Malaysia \\ ${ }^{2}$ Reconstruction and Projects Department, University of Baghdad, Baghdad, Iraq
}

Received 22 March 2018; accepted 19 December 2018

\begin{abstract}
Advances in the telecommunication and broadcasting sectors have increased the need for networking equipment of communication towers. Slender structures, such as towers, are sensitive to dynamic loads, such as vibration forces. Therefore, the stability and reliability performance of towers can be maintained effectively through the prompt detection, localization, and quantification of structural damages by obtaining the dynamic frequency response of towers. However, frequency analysis for damaged structures requires long computational procedures and is difficult to perform because of the damages in real structures, particularly in towers. Therefore, this study proposed a correlation factor that can identify the relationship between frequenciesunderhealthy and damaged conditions of ultra high performance fiber-reinforced concrete (UHPFRC) communication towers using particle swarm optimization. The finite element method was implemented to simulate three UHPFRC communication towers, and an experimental test was conducted to validate and verify the developed correlation factor.
\end{abstract}

Keywords: communication towers, ultrahigh performance concrete (UHPC), dynamic nonlinear analysis, frequency response, correlation factor, finite element method, particle swarm optimization (PSO).

\section{Introduction}

Damages caused by various factors may occur in structures during their intended lifespan. These damages must be located and measured to ensure the safety of structures. Many researchers have proposed techniques for detecting structural damages based on different types of structural characteristics or responses. The natural frequencies of structures are the most appropriate response candidates for damage detection (Kaveh \& Zolghadr, 2015).

Determining the change in natural frequency can be used as a damage detection approach in structural assessment. This method offers the advantages of fast and easy frequency measurements (Sinou, 2009). Several investigations have been conducted to identify structural damages by using natural frequency approaches. Yang, Swamidas, and Seshadri (2001) used frequency change against crack depth in 3D plots, including location, to detect a saw cut in a beam made of aluminum material. The result of the obtained frequency change contour lines were plotted and overlaid. The intersection points yielded the actual depth and location of the crack. Ren and De Roeck (2002) proposed a method for predicting the location and severity of a damage by using changes in frequencies, mode shapes, and finite element methods (FEMs). Their method, which was validated using simulated and real measurement data, yielded satisfactory results. Kim and Stubbs (2002) introduced an algorithm that uses only low modes of vibration to identify the location and intensity of structural damage. The algorithm was verified on a two-span continuous beam and achieved good accuracy in indicating the location and severity of damage. Kessler et al. (2002) investigated the influences of different types of damage (delamination, impact damage, drilled-through holes, bending-induced cracks, and fatigue damage) on frequency response by using clamped composite plates. The authors concluded that fatigue damage is the only distinguishable type of damage with in the low-frequency range. Smith and Shust (2004) studied bounding natural frequencies in structures wherein natural frequency is affected mainly by the given boundary conditions, cross section, material function sensitivity, and size function sensitivity. Sutar (2012) used Finite element method (FEM) on a cantilever beam under cracking and examined the relationship among the natural frequen-

${ }^{\star}$ Corresponding author. E-mail: farzad@fhejazi.com 
cies of a model with crack depth and location. The results showed that the natural frequency of the model decreases with an increase in crack depth and location from the fixed end. The dynamic analysis of tall slender structures is generally performed in the frequency domain based on the characteristic-dependent frequency of the mechanical properties and loads on the structure.

Towers are tall slender structures where radio transmitters and their accessories are installed. These structures house a considerable number of equipment that transmits electromagnetic waves and ensure the proper operation of various services, such as mobile communication, television, and radio. However, the structural system of towers is susceptible to damage due to the heavy wind effect. Thus, the material and geometric properties, boundary conditions, and system connectivity of these structures can affect system performance if they are not designed appropriately (Guidorzi, Diversi, Vincenzi, Mazzotti, \& Simioli, 2014). Structural damages reduce stiffness, thereby decreasing the natural frequency of a system. Therefore, the dynamic response of a structure must be investigated, particularly when the first natural frequency of the structure is less than $1 \mathrm{~Hz}$.

Negm and Maalawi (2000) proposed optimization models of a wind turbine tower. These models showed thatoptimizing the weighted sum of the natural frequencies of a system represents the objective function and ensures balanced improvement in stiffness and mass. Grünbaum (2008) calculated the frequencies of tall building structures and displacements using 3D FEM with three different structures and compared their behavior to wind load. The results showed that frequency increases with the stiffness of a building, where as it decreases as building weight increases. Antunes, Travanca, Varum, and André (2012) presented a dynamic monitoring system of two tall slender steel telecommunication towers with a height of $50 \mathrm{~m}$ located in Portugal by using the frequency domain. The results indicated that stiffness loss occurs due to the connections and degradation of existing materials. Saisi, Gentile, and Guidobaldi (2015) explored the dynamic monitoring system of the $54.0 \mathrm{~m}$-tall Gabbia Tower in Mantua, Italy using damage identification based on shifts in natural frequencies. The effects of post-earthquake conditions and temperature on the frequency of the tower were also investigated. The results indicated increases in temperature and modal frequencies, whereas the natural frequency of the fundamental modes was reduced because of the far-field seismic activities. Moreover, the authors found that temperature variation has no considerable effect on the frequency of the tower.

Several investigative approaches have been used to identify damages in civil structures and to differentiate various types of damage. Diverse approaches have been undertaken. For example, some investigations focus on identifying damage locations, whereas others rely on monitoring damage initiation. The optimal solutions for any system can be defined as feasible solutions with an objective function value and any other feasible solutions attained through the selection of values for a set of parameters that satisfy all the constraint solutions (Rardin, 1998). Many parameters and variations affect the extent of damage and inter operation of accurate decision data on damage occurrence. In recent years, various optimization techniques have been implemented to enhance the accuracy of the damage detection and health monitoring systems of structures. Mhaske and Shelke (2000) detected the depth and location of a crack in a cantilevered beam using the vibration measurement test with the aid of an artificial neural network (ANN) and a genetic algorithm (GA). The authors found that GA is an accurate search method for obtaining the desired results in vibrating structures or beams. The validation of the experimental results with ANN showed an acceptable similarity. Paultre, Weber, Mousseau, and Proulx (2016) developed a sensitivitybased damage identification approach. The system works based on the model update applied to a full-scaletwo-story structure made with high-performance concrete (HPC) under earthquake excitations. The investigation was performed to obtain mode shapes, modal damping, and resonant frequencies. Dua, Watkins, Wunsch, Chandrashekhara, and Akhavan (2001) proposed a new classification approach for identifying damages caused by impact on composite plates using ANN and FEM. Compared with other soft computing tools, particle swarm optimization (PSO) is efficient and requires only a few function evaluations to yield the same quality or improve the results (Ashour \& Rishi, 2000; Dong, Xu, \& Lin, 2017; Alaghebandha, Hajipour, \& Hemmati, 2017). Kazemi et al. (2011) proposed an ANN and a PSO based on certain procedures to determine the depth and location of cracks in cantilever beams. The first three natural frequencies of beams were obtained from FEA and applied as inputs for ANN. PSO was applied to train ANNs to predict the depth and location of cracks. The results are in good agreement with the actual data, thereby exhibiting the feasibility of using an ANN that is trained with only natural frequency data.

Begambre and Laier (2009) reported that improved results were obtained in identifying structural damage when data frequency and FE analyses were performed on a 10bar truss and crack-free beam, which effectively determined damage location using the PSO-simplex algorithm. As warm optimization algorithm has also been applied to detect structural damage in truss by observing changes in vibrations using ant colony optimization (Majumdar, Nanda, Maiti, \& Maity, 2014), which exhibited varying levels of success in accurately determining structural damage from the results. Nhamage, Lopez, and Miguel (2016) proposed a hybrid stochastic/deterministic optimization algorithm for detecting damage in a cantilever beam due to changes in vibrational frequencies. They reported that the model performed efficiently in detecting damage from a cantilever beam.

The aforementioned literature review shows that natural frequencies are appropriate parameters for assessing the health condition of structures because frequencies depend on stiffness and indirectly reflect the stability and 
strength of a structure. The dynamic frequency response of healthy and damaged structures can be used to identify any damage. However, accomplishing this task is difficult when numerical and experimental methods that require numerous calculations are used. Therefore, this study proposed a dynamic frequency correlation factor for identifying the relationship between frequenciesunderhealthy and damaged conditions for ultrahigh performance fiber-reinforced concrete (UHPFRC) communication towers using PSO.

\section{Dynamic response of the structure}

In the past, several on-model-based damage identification algorithms have been developed using different dynamic characteristics, such as modes, shapes, and natural frequencies. The change in natural frequency is associated with the degradation of a structure. Thus, this parameter can be an indicator of the stability of a structure and the preventive measures that can be taken to save cost and the lives of inhabitants. Frequency can be used to evaluate the dynamic performance of a structure because it affects the stability and strength of the structure.

The dynamic analysis of tall slender towers is commonly performed in the frequency area in consideration of the frequency-dependent and mechanical properties of a building. In accordance with the Eurocodes EN 1991-1-4 (CEN, 2005), EN 1993-3-1 (CEN, 2006), simplified quasistatic design procedures can be adopted with suitable gust response factors that depend on various parameters, such as damping factor, first natural frequency, and structural characteristic. In the design approach of the Eurocodes, the first natural frequency is a key parameter for estimating the response of a structure. The natural frequencies of towers, with variations in height and geometric characteristics, have been reported by different researchers.

The evaluation of frequency using numerical and experimental methods requires numerous calculations. Therefore, this study proposed a correlation factor for identifying the relationship between frequencies under healthy and damaged conditions of structures. The result can be used to identify cracks.

\section{A correlation factor of damage frequency of UHFPRC communication tower}

To identify the relationship between the frequencies under healthy and damaged conditions of UHPFRC communication towers, a correlation factor was used by applying PSO, as presented in Eqn (1):

$$
f_{\text {damage }}=\text { correlation factor } \times f_{\text {healthy }} \text {, }
$$

where: $f_{\text {damage }}$ - damage frequency of the tower, $f_{\text {healthy }}-$ healthy frequency of the tower.

To formulate the damage frequency ratio (Eqn (1)), the frequency of the structure under healthy condition should be determined (through numerical simulation or experimental test). However, as mentioned earlier, temperature variation does not affect frequency response.
A new development was achieved with regard to the capability of the indicator as a correlation factor in detecting and relatively quantifying damages. Three key points must be considered in its development: (a) the objective function must be formulated, (b) a clear method for solving the optimization problem must be developed, and (c) the convergence criteria must be defined. These itemized points are discussed in the succeeding sections. A communication tower made of UHPFRC with a hollow circular section was considered. This tower consisted of three segments that were connected to one another using bolts and nuts at the joints.

\section{Considered communication tower}

The UHPFRC communication tower used in this study was based on an actual tower located in Malaysia with a height of $30 \mathrm{~m}$. The tower model was composed of three segments, and each segmentwas $10 \mathrm{~m}$ high, bolted together at joint locations, and fixed to a reinforced concrete foundation base with a length, width, and depth of $4 \times 4 \times 1 \mathrm{~m}$ (Figure 1).

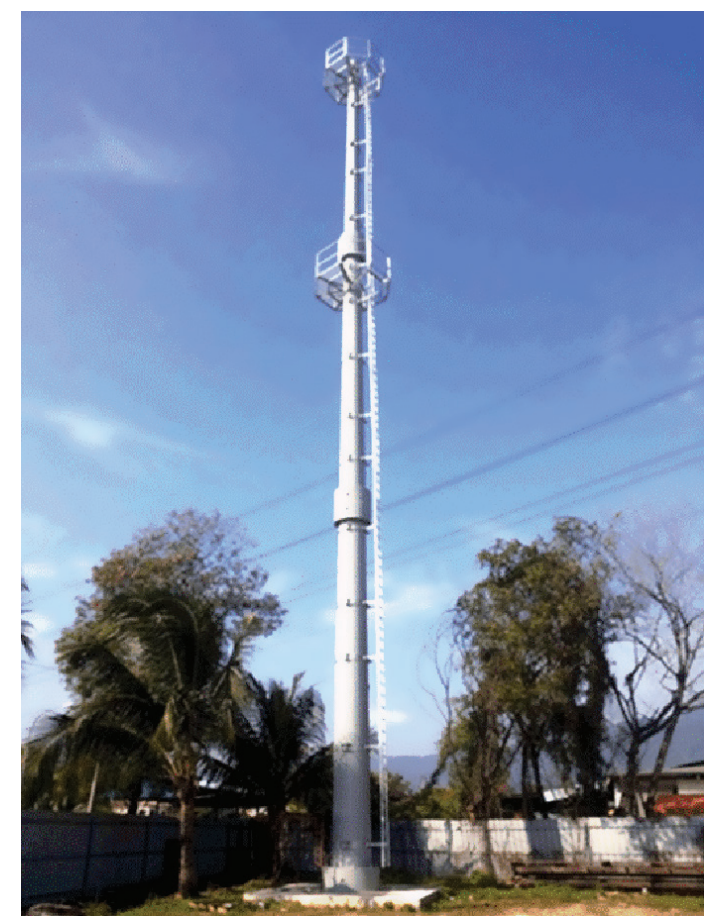

Figure 1. UHFPRC communication tower located in Malaysia

A fixed connection was applied to provide sufficient lateral stiffness for the tower and to link the prestress reinforced concrete segmental sections to one another using bolts and nuts. The length and diameter of the bolt were $1000 \mathrm{~mm}$ and $25 \mathrm{~mm}$, respectively, in the connection joint. Meanwhile, the bolts in the foundation connection were $1000 \mathrm{~mm}$ and $32 \mathrm{~mm}$ in length and diameter, respectively. Each segment was arranged in eight tendons, and each connection was arranged in eight holes for the bolts. The total mass density for the ultrahigh performance concrete was $2500 \mathrm{~kg}$ per $\mathrm{m}^{3}$ using a grade of $150 \mathrm{MPa}$, a Young's 


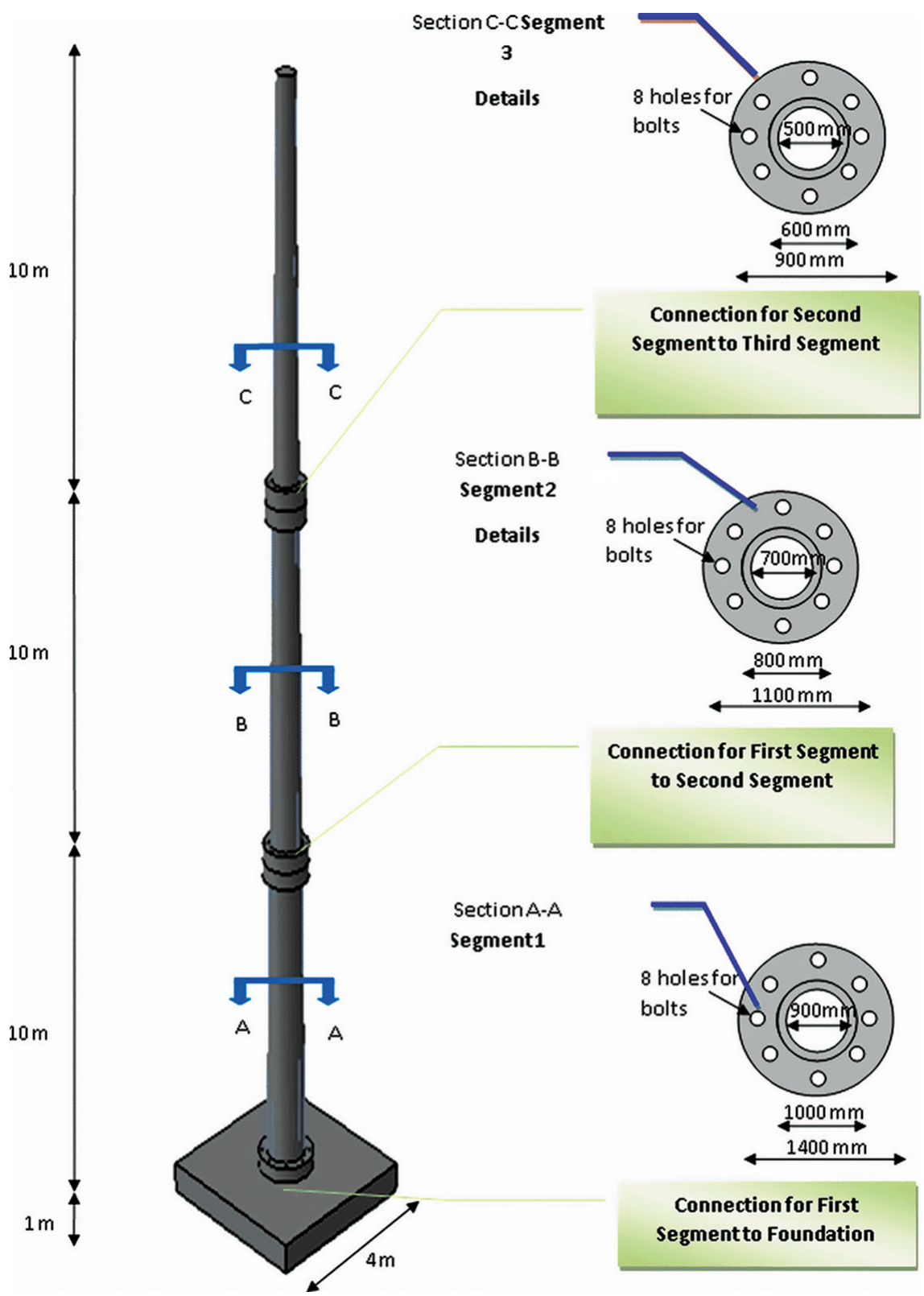

Figure 2. Developed FEM for typical UHPFRC communication tower (15 m, $30 \mathrm{~m}$ and $45 \mathrm{~m}$ height)

modulus of elasticity of $55 \mathrm{GPa}$, and a Poisson's ratio of 0.18 . The segments were internally prestressed using tendons with a diameter of $15.2 \mathrm{~mm}$ and a Young's modulus of $200 \mathrm{GPa}$. Figure 2 shows the modeled tower.

FEM was used to develop three communication towers with heights of 15,30 , and $45 \mathrm{~m}$ to establish the frequency correlation factor. The tower with a height of $30 \mathrm{~m}$ was tested experimentally to verify the results and develop the PSO algorithm for damage correlation, whereas the towers with heights of $15 \mathrm{~m}$ and $45 \mathrm{~m}$ were used to validate the algorithm. Different damage scenarios were created using FEM. The damages involved individually removing one to six bolts from each connection for the full-scale tower. Then, 87 cracks, which consisted of vertical and horizontal cracks at every $1 \mathrm{~m}$ of the communication tower, were simulated.

\section{Development of FEM}

Numerical analysis was conducted to evaluate the modal parameters (particularly the natural frequencies) of the precast UHPFRC communication tower under various conditions. The performance of the communication tower was investigated under free vibration in healthy and different damage cases. A 3D nonlinear finite element program, ABAQUS (Dassault Systèmes Simulia Corp., 2014), was utilized to model the three UHPFRC communication towers with heights of $15 \mathrm{~m}, 30 \mathrm{~m}$, and $45 \mathrm{~m}$ under healthy and damaged conditions, as shown in Figure 3 . The $30 \mathrm{~m}$ tall tower was tested experimentally to verify the numerical results (Table A.2, Appendix) and develop the PSO algorithm for damage correlation, whereas the $15 \mathrm{~m}$ and $45 \mathrm{~m}$ tall towers were used to validate the algorithm. Then, $3 \mathrm{D}$ finite element software with an eight-node solid element was used 


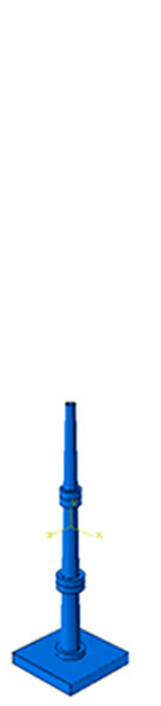

(a) $15 \mathrm{~m}$ height

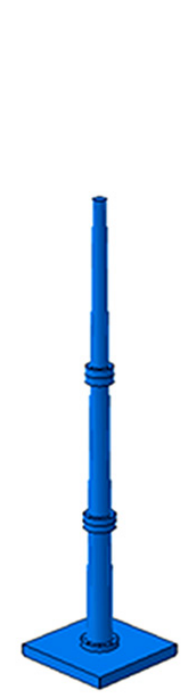

(a) $30 \mathrm{~m}$ height

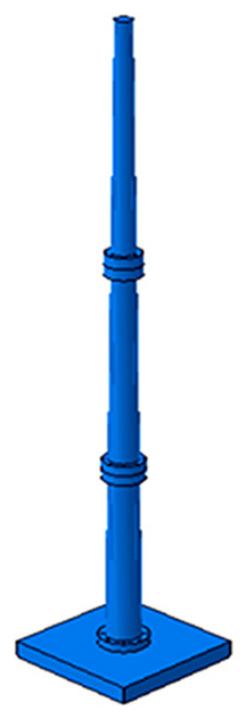

(a) $45 \mathrm{~m}$ height

Figure 3. Developed UHPFRC communication towers with $15 \mathrm{~m}, 30 \mathrm{~m}$, and $45 \mathrm{~m}$ height

to simulate the three concrete UHPFRC communication towers with heights of $15 \mathrm{~m}, 30 \mathrm{~m}$, and $45 \mathrm{~m}$.

A two-node linear 3D truss element was used to model the reinforcing bar and pressurizing tendon elements that were embedded into the concrete. Screws and nuts were used to integrate the different parts of the proposed connection. For the segment connection, the screw and nut were created as solid parts with the bolts having a length and diameter of $1000 \mathrm{~mm}$ and $25 \mathrm{~mm}$, respectively. The diameter of the bolts for the foundation and the first segment connection was $32 \mathrm{~mm}$.

The structured and sweep technique was adopted for meshing. All the models meshed with a sieve of $150 \mathrm{~mm}$ are shown in Figure 4.

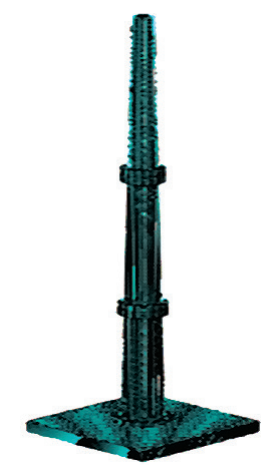

Figure 4. UHFPRC Tower Mesh (15 m, 30 m, and $45 \mathrm{~m}$ height)

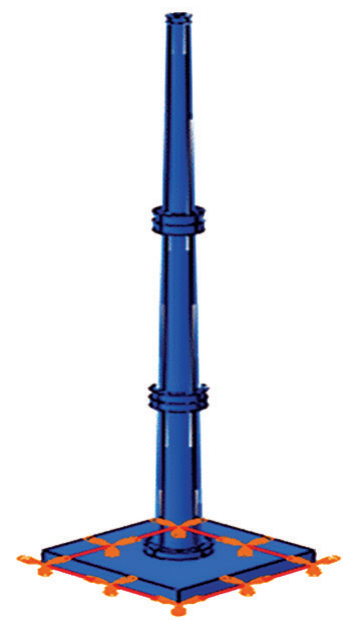

Figure 5. Applying boundary condition for UHFPRC communication tower

A fixed boundary condition was applied to the UHPFRC communication tower foundation, as shown in Figure 5. The boundary condition is defined in Eqn (2):

$U_{1}=0, U_{2}=0, U_{3}=0, U R_{1}=0, U R_{2}=0, U R_{3}=0$,

where $U$ is the translation, and $U R$ is the rotation.

The Lanczos eigen solver analysis was implemented to generate frequency.

\section{Frequency results of the $\mathbf{3 0} \mathrm{m}$ UHPFRC tower}

Numerical analysis was conducted to investigate the frequency response of the UHPFRC communication tower under healthy condition for the first 11 modes of vibration before damage, as listed in Table 1, for the first 11 modes of vibration before damage.

Figure 6 shows the mode shapes that correspond to the frequencies of the UHPFRC communication tower under healthy condition.

A full-scale UHPFRC communication tower in a healthy state was tested experimentally via an experimental modal analysis test using a Kistler impact hammer (model 9728A20000) to evaluate the frequency response and verify the numerical frequency responses of the tower, as shown in Figure 7. The signal was measured using three accelerometer sensors attached to the specimen to determine the first 11 natural frequencies.

Table 1. Verification result of the experimental and numerical tower

\begin{tabular}{|l|c|c|c|c|c|c|c|c|c|c|c|}
\hline Mode No. & Mode & $\begin{array}{c}\text { Mode } \\
1\end{array}$ & $\begin{array}{c}\text { Mode } \\
3\end{array}$ & $\begin{array}{c}\text { Mode } \\
4\end{array}$ & $\begin{array}{c}\text { Mode } \\
5\end{array}$ & $\begin{array}{c}\text { Mode } \\
6\end{array}$ & $\begin{array}{c}\text { Mode } \\
7\end{array}$ & $\begin{array}{c}\text { Mode } \\
8\end{array}$ & $\begin{array}{c}\text { Mode } \\
9\end{array}$ & $\begin{array}{c}\text { Mode } \\
10\end{array}$ & $\begin{array}{c}\text { Mode } \\
11\end{array}$ \\
\hline $\mathrm{f}_{\mathrm{EXP}}$ & 0.9 & 1.13 & 3.45 & 8.63 & 15.36 & 18.1 & 42.83 & 79.21 & 101.56 & 119.46 & 138.49 \\
\hline $\mathrm{f}_{\cdot \mathrm{FE}}$ & 0.93 & 0.94 & 3.8 & 8.87 & 17.79 & 20.1 & 41.35 & 74.15 & 104.14 & 113.86 & 137.44 \\
\hline$\left[\left(\mathrm{f}_{\mathrm{EXX}}-\mathrm{f}_{\mathrm{FE}}\right) / \mathrm{f} \cdot \mathrm{EXP}\right] \%$ & -0.03 & 0.19 & -0.35 & -0.24 & -2.43 & -2 & 1.48 & 5.06 & -2.58 & 5.6 & 1.05 \\
\hline
\end{tabular}




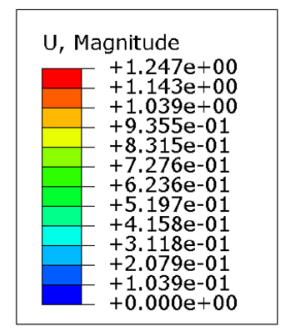

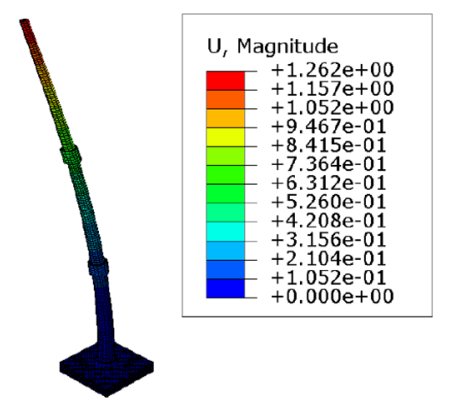

mode $1(f=0.93)$

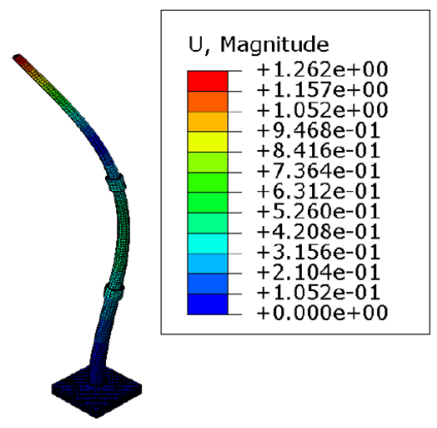

mode $2(f=0.94)$

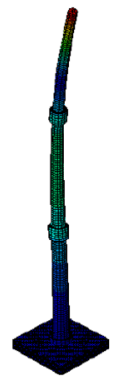

mode $3(f=3.8)$
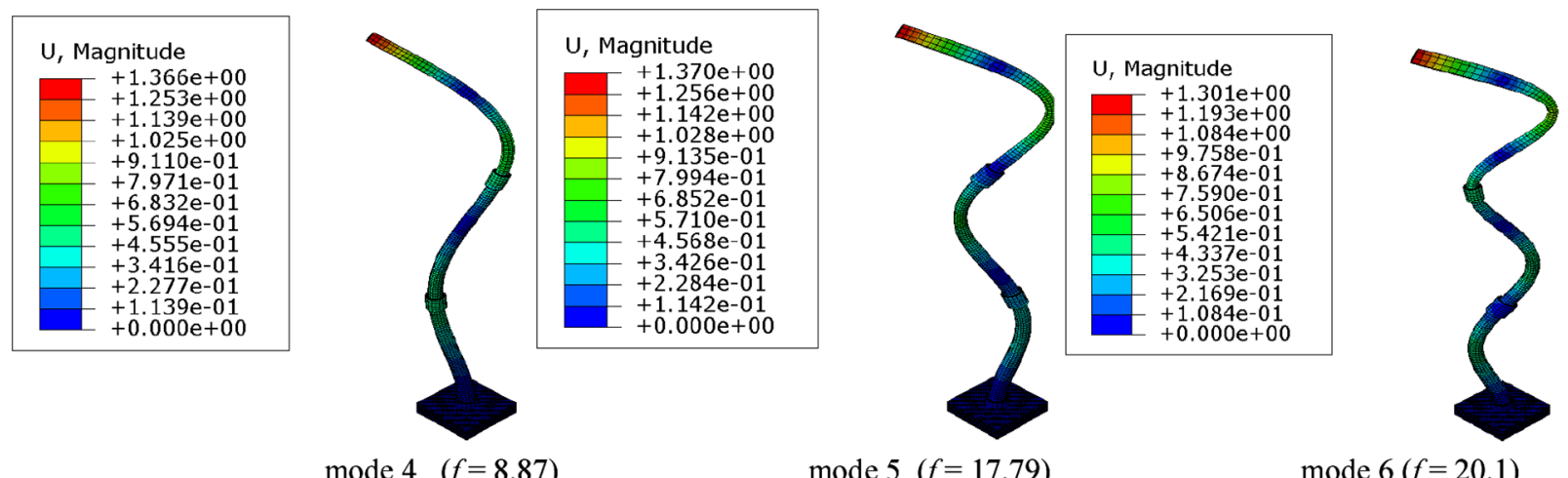

mode $4 \quad(f=8.87)$

mode $5(f=17.79)$

mode $6(f=20.1)$

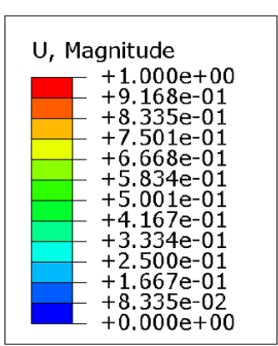

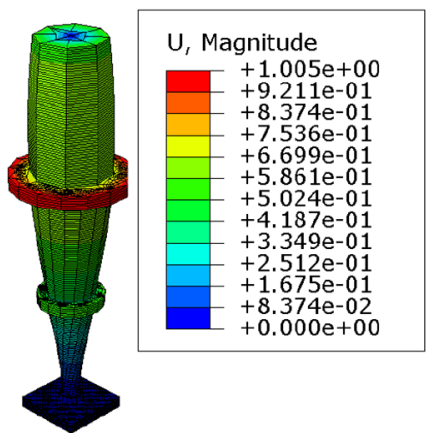

mode $7(f=41.35)$

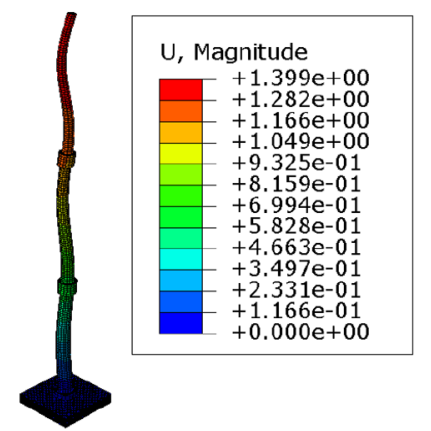

mode $8(f=74.15)$

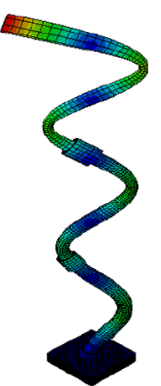

mode $9(f=104.14)$

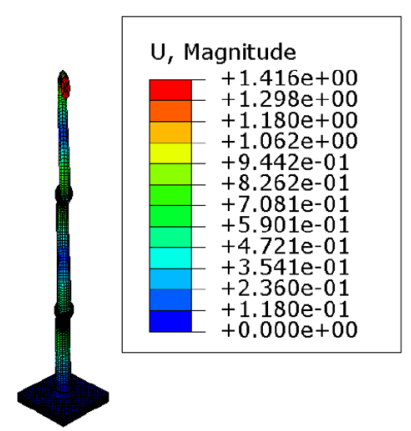

mode $11(f=137.44)$

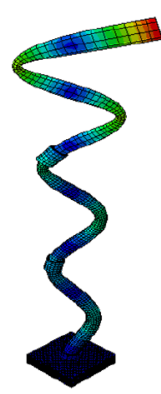

mode $10(f=113.86)$

Figure 6. Mode shapes of the UHPFRC communication tower 


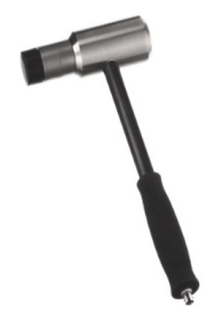

Figure 7. Impact hammer

The test procedures are described as follows.

1. Three Kistler accelerometers (model 8702B50M1) were used to record acceleration response, as shown in Figure 8. Each accelerometer was placed in a specific position.

2. The position of the knocking point was marked.

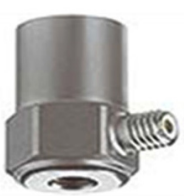

Figure 8. Accelerometer

3. The data logger was set up, and the hammer and accelerometers were connected to the data logger to start knocking, as shown in Figure 9.

The frequencies of the structures can be obtained from the time history of the acceleration response by using fast Fourier transform (FFT). The accelerometers were installed, and the response signals were administeredusingan eight-channelsignal analyzer called OROS. The equipment was used to convert input analog signals to digital form

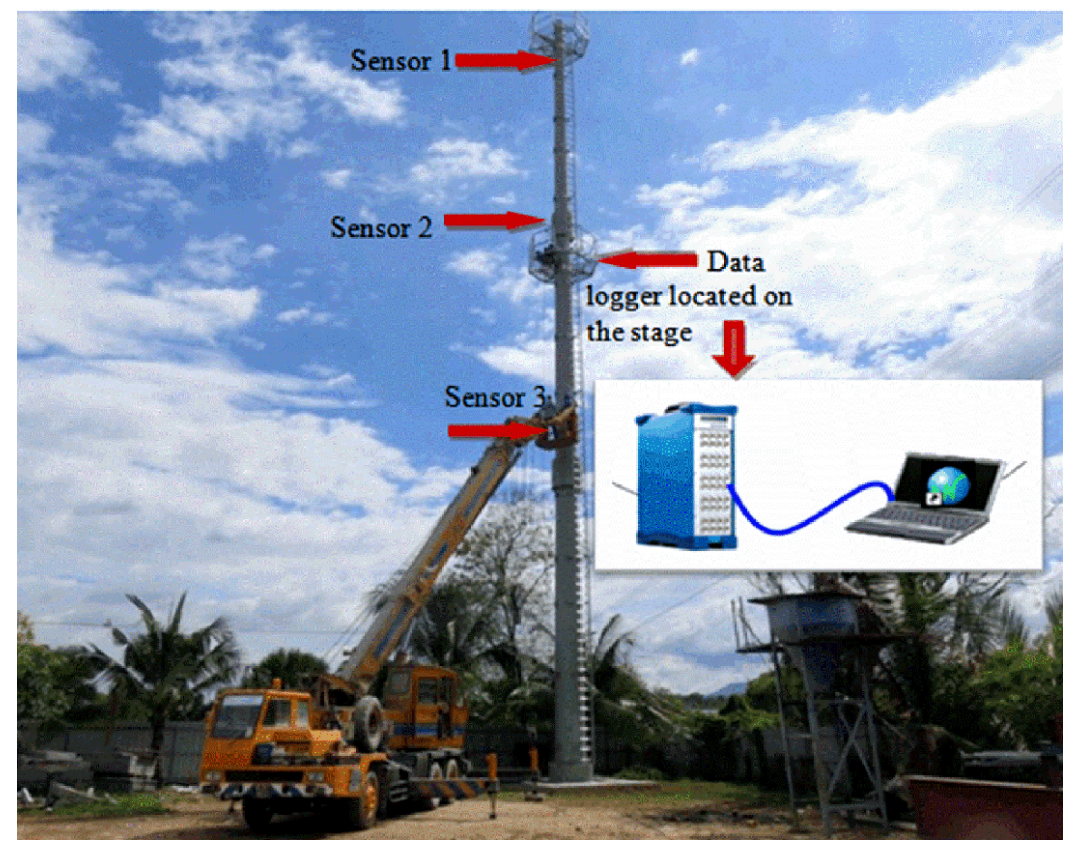

(a) Setup the data logger at real tower

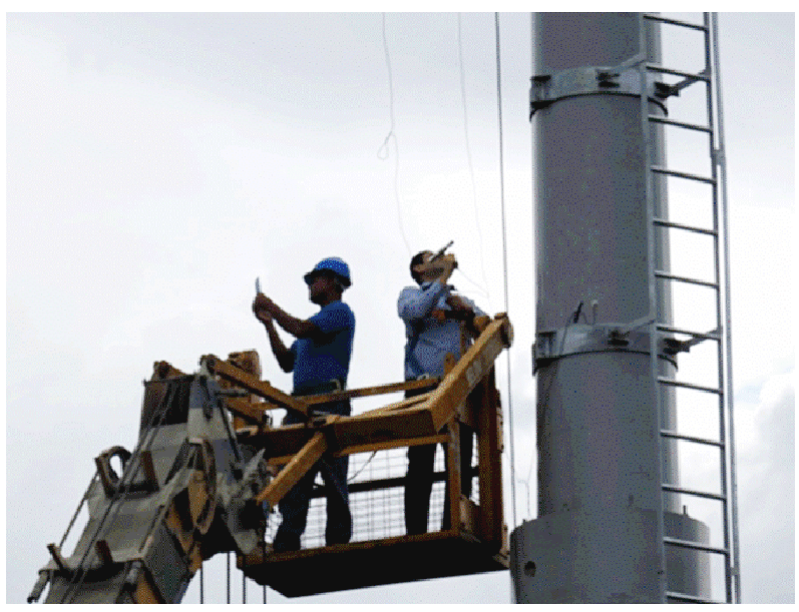

(b) Knock different points on the tower

Figure 9. Experimental modal test of UHFPRC communication tower 


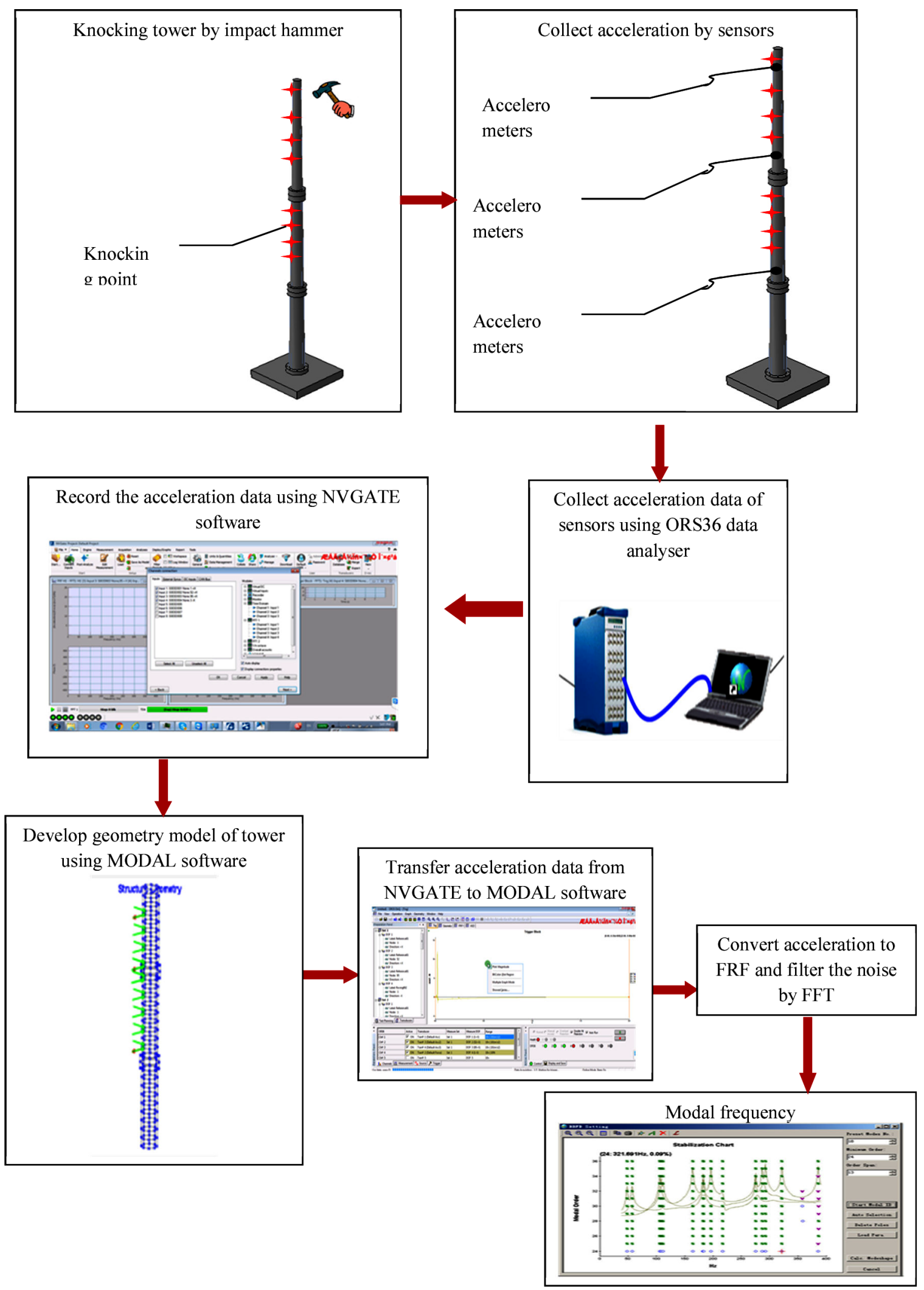

Figure 10. Functions for FRF Generation for UHPFRC communication tower 


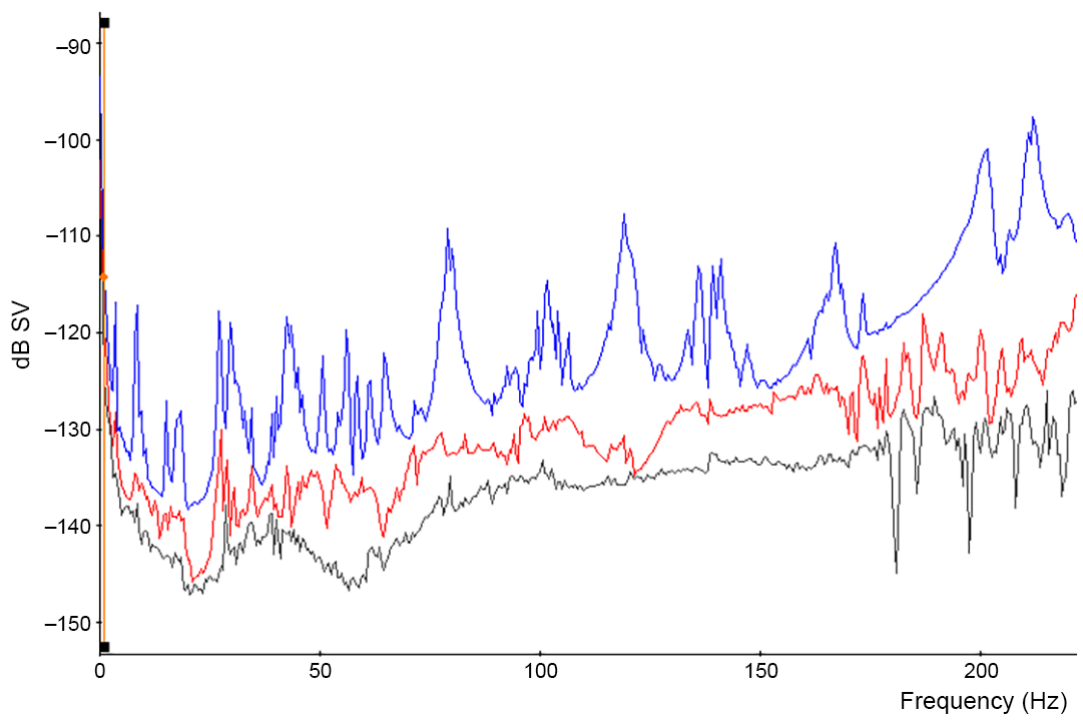

Figure 11. FRFs recorded at different accelerometer points for UHFPRC tower

through transducers. The data were recorded in the analyzer, and then converted to FFT using NVGATE software (Oros Gmbh, 2006). Then, NVGATE software exported the FFT results in universal file format (UFF). The MODAL utility program read the UFF files and exported them as frequency response function (FRF) files. The acceleration data corresponded to a frequency signal bandwidth of $400 \mathrm{~Hz}$ with $22 \mathrm{FRF}$ data points. The sampling frequency was considered as 400 (sampling interval time was set as 0.0025 seconds) and the measured signal duration was set as 2 seconds. The resolution of the estimation was made by data analyzer and Modal Software during test data and its functioning to setup the data acquisition. From the experimental modal analysis, the dynamic properties of the tower, including the FRFs and natural frequencies, were determined during each healthy state. The modal analysis procedure for the UHPFRC communication tower is presented in Figure 10.

Table 1 shows the average frequency values determined in the dynamic tests for the tower on site. These values were used to verify the numerical analysis results. The frequency peak was $0.9 \mathrm{~Hz}$, with the highest at $138.49 \mathrm{~Hz}$. In accordance with the Eurocodes EN 1991-1-4 (CEN, 2005), EN 1993-3-1 (CEN, 2006), AS/NZS 1170.2 (Joint Technical Committee, 2004), resonant response is important when the first natural frequency of the structure is below $1 \mathrm{~Hz}$. Therefore, dynamic analysis must be conducted to determine resonance response compared with background response. Resonant frequency must be considered when tracking the changes in the frequency, and it can be used as an indicator of damage.

Figure 11 shows the FRF graph recorded by three sensors. The different frequency peaks, which depicted the first 11 modes through the frequency bandwidth within the range of $0-400 \mathrm{~Hz}$ generated by MODAL software, were recorded. Thus, the maximum number of modes that can be captured with high precision through the selected setup is determined.

\section{Validation of FEM}

Experimental analysis was conducted to evaluate and verify the numerical frequency response of the $30 \mathrm{~m}$ tall communication tower under healthy condition for the first 11 modes, as listed in Table 1.

A convergence study was conducted to verify the material properties and meshing size of the suggested FEMs of the UHPFRC communication tower used in the optimization process.

The first 11 vibration modes before damage was obtained from the modal experimental test were compared with the first 11 modes of the FEMs. The results indicated that the maximum variation obtained in the frequencies from FEM and the experimental results was 5.6\% for the UHPFRC communication tower. The difference in variation was less than $20 \%$ for all the results of the full-scale tower, there by proving that ABAQUS software is an appropriate tool for predicting the behavior of UHPFRC communication towers.

\section{Development of the PSO algorithm for the correlation factor of damage frequency of UHPFC communication tower}

The optimization technique was applied to generate an optimized correlation factor of the damage frequency of a communication tower. Three major points were considered before optimizing the damage frequency correlation ratio:

1) Formulation of the objective function;

2) Use of the PSO technique to optimize the damage frequency correlation ratio;

3) Use of convergence criteria (all the parameters are described in the following section).

\subsection{Objective function}

In this study, the PSO algorithm was used to optimize the correlation factor of damage frequency of communica- 
tion tower and to determine the optimal values for the unknown set of coefficients, $F_{1}, F_{2}$ and $F_{3}$, from the solution space. A small difference was noted between the actual values and the predicted by applying the final optimized algorithm. Moreover, the convergence of the current method was determined by terminating the search process after identifying the set of coefficients that was able to minimize the objective function. MATLAB programming software was used to simulate and optimize the proposed damage frequency correlation ratio. The mean absolute error (MAE) objective function was used as follows (Hanoon, Jaafar, Hejazi, \& Abdul Aziz, 2017a):

$$
M A E=\frac{1}{n} \sum_{i=1}^{n}\left|f_{\text {dactual }}-f_{\text {dpred }}\right|,
$$

where $f_{d p r e d}$ is the predicted value of the damage frequency of the communication tower, $f_{\text {dactual }}$ is the actual value of the damage frequency of the communication tower, and $\mathrm{n}$ is the number of data samples.

Different damage scenarios were created using FEM (see Appendix, Tables A.1-A.3). The damages consisted of sixty $200 \mathrm{~mm}$ cracks (30 vertical and 30 horizontal cracks at $1 \mathrm{~m}$ intervals), as shown in Figure 12. Then, damage types and locations were set as the damage index from Cases 0 to 6 .

The proposed process was simulated using MATLAB to optimize the frequency of damage. This correlation factor can be determined using the following equation:

$$
f_{\text {Damaged }}=c_{1} \times\left(F_{1} \times D I^{2}+F_{2} \times D I+F_{3}\right) \times f_{\text {Healthy }},
$$

where $f_{\text {Damaged }}$ and $f_{\text {Healthy }}$ are the frequencies under the damaged and healthy conditions of the tower. $c_{1}$ is a constant that depends on the mode number. $F_{1}, F_{2}$, and $F_{3}$ are the unknown coefficients. DI is the damage index (types and locations of damage), which is defined as:

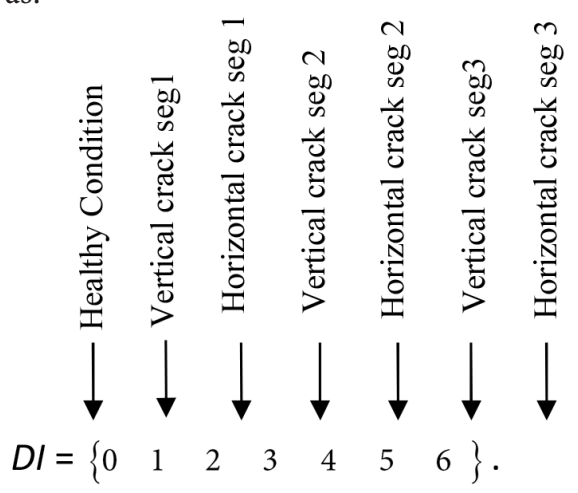

\subsection{PSO algorithm}

The initial PSO technique is a form of evolutionary computation process that was first proposed by Eberhart and Kennedy (1995). This technique is based on the social behavior of birds (particles), i.e. flocking. PSO is widely used because of its robustness, global convergence capability, and easy implementation (Xie, Wang, \& Li, 2012; Chagwiza, Jones, Hove-Musekwa, \& Mtisi, 2018).

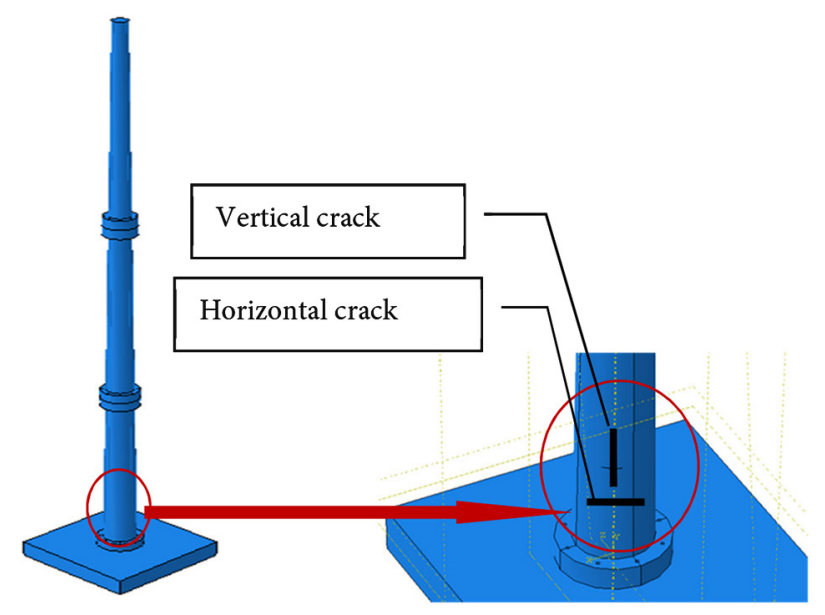

Figure 12. Vertical and horizontal crack for UHPFC communication tower

As discussed earlier, the PSO algorithm has been applied to a variety of optimization problems. In PSO, Eqns (5) and (6) (Kulkarni \& Venayagamoorthy, 2011) are used to update the velocity and location of every particle while conducting the search process. Shi and Eberhart (1998) suggested using inertial weight $(w)$ to improve the convergence rate of the PSO algorithm. Using the inertial weight helps set the particle contribution rate from their previous velocity value to their current velocity value. Through the entire search process, the velocity and position of every particle can be updated as:

$$
\begin{gathered}
V_{i}(t+1)=w \times V_{i}(t)+c_{1} \times \operatorname{Rand}(\cdot)_{1} \times\left[\text { pbest }_{i}(t)-X_{i}(t)\right]+ \\
c_{2} \times \operatorname{Rand}(\cdot)_{2} \times\left[\text { gbest }_{i}(t)-X_{i}(t)\right] \\
X_{i}(t+1)=X_{i}(t)+V_{i}(t+1)
\end{gathered}
$$

where $V_{i}$ and $X_{i}$ refer to the velocity and location of the studied particles, respectively; $\operatorname{Rand}(\cdot)_{1}$ and $\operatorname{Rand}(\cdot)_{2}$ represent the random numbers that are uniformly distributed from 0 to 1 and are regarded to be generally equal; $c_{1}$ and $c_{2}$ refer to the acceleration coefficients; pbest refers to the best location for every particle under study; and gbest denotes the best global position for all the studied particles. The acceleration coefficients denote the "trust" settings that indicate the degree of confidence in the best solution obtained by individual particles (cognitive parameter) or by the entire particle swarm $\left(c_{2}\right.$, social parameter). In Eqn (3), w refers to the inertial weight, which is a scaling factor that helps control the exploratory ability of the entire swarm and also scales the existing velocity value that influences the revised value of the velocity vector. The original PSO algorithm (Eberhart \& Kennedy, 1995) does not contain the inertial weight because this was introduced later by Hanoon et al. (2017a) to improve the convergence rate.

Figure 13 describes the particle velocities and the revised positions for the 2D parameter space (Hanoon, Jaafar, Hejazi, \& Abdul Aziz, 2017b). Here, the particle velocity contains three major vectors. Vector 1 is the mo- 


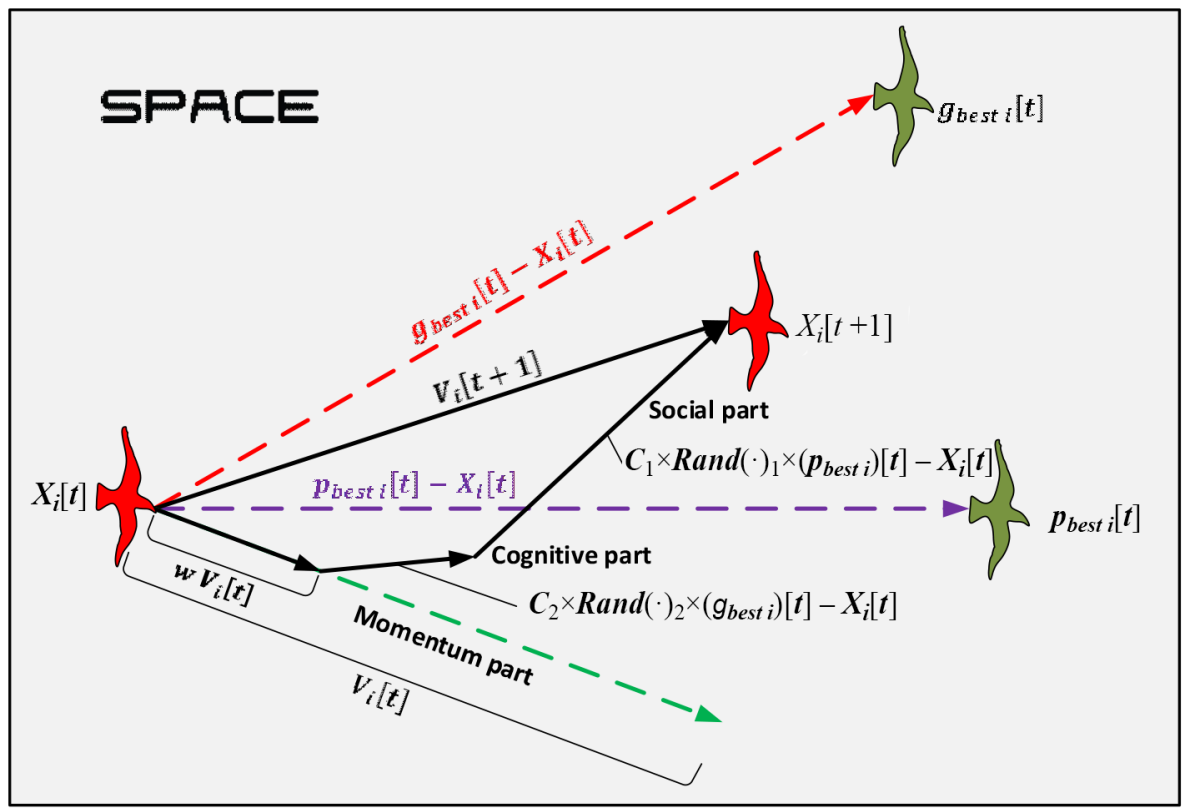

Figure 13. Description of the velocity and position updates in PSO for a two-dimensional parameter space

mentum or the inertial component that depends on the velocity of the particle at a previous stage. This vector enables the particle to continue along its existing trajectory. Vector 2 represents a cognitive or a memory component, which is derived based on the best particle position during all the iterations. This vector helps attract particles to their previous best position within the solution space. Finally, Vector 3 is the social or swarm component, which helps particles gravitate to the best positions in the swarm.

\subsection{Convergence criteria}

In accordance with the iterative nature of a PSO search, the application of convergence criteria will stop the optimization procedure. The two most widely used convergence criteria are the minimum error required to achieve the optimum value of the objective function (the degree of correlation between the frequency estimated by FEM and the frequency predicted by PSO) and the maximum iterations of the algorithm. The minimum error criterion assumes the previous information of the global optimum value, where as the nature of the optimization problem de- termines the maximum number of iterations. In the case of prior knowledge of the optimum value, mathematical algorithms can be used to resolve the problems. However, these methods are inapplicable to practical structural optimization issues without prior information of the optimum value.

The main PSO parameters identified by Hanoon et al. (2017a) are listed in Table 2, and the convergence criteria used in the PSO in this research are listed in Table 3.

\section{Implementing PSO for predicting the correlation factor of damage frequency of UHPFRC communication tower}

Applying the PSO algorithm helps determine the optimized solution by calculating the best and optimal values for the unknown coefficients of $F_{1}, F_{2}$, and $F_{3}$, which consequently helps improve the performance of the damage frequency correlation ratio. In this study, we incorporated the PSO algorithm to create a correlation factor of the damage frequency of a communication tower that was expected to decrease the errors between the actual

Table 2. Main PSO parameters

\begin{tabular}{|ll|}
\hline \multicolumn{1}{|c|}{ Description } & \multicolumn{1}{c|}{ Details } \\
\hline$N$ is particles number & $\begin{array}{l}\text { A typical range is } 10-40 . \text { For some complicated or special problems, the } \\
\text { number can be increased to } 50-100 .\end{array}$ \\
$\begin{array}{l}\text { It is determined by the problem to be optimized. } \\
W \text { is particles Dimension }\end{array}$ & $\begin{array}{l}\text { Usually is set to a value less than 1, and for faster convergence, } w=0.7 \text { is } \\
\text { considered (Lavanya \& Udgata, 2011). It can also be updated during iterations. }\end{array}$ \\
$\begin{array}{ll}\text { Vectors containing the lower and higher bounds } \\
\text { of the } n \text { design variables, respectively, } \mathrm{xL}, \mathrm{xU}\end{array}$ & $\begin{array}{l}\text { They are determined by the problem to be optimized. Different ranges for } \\
\text { different dimensions of particles can be applied in general. }\end{array}$ \\
$\begin{array}{l}\text { Cognitive and social parameters } \\
\text { Usually } c_{1}=c_{2}=1.494 \text { (Lavanya \& Udgata, 2011). Other values can also be } \\
\end{array}$ &
\end{tabular}


Table 3. PSO convergence parameters

\begin{tabular}{|ll|}
\hline \multicolumn{1}{|c|}{ Description } & \multicolumn{1}{c|}{ Details } \\
\hline$T_{\max }$ is the maximum value of iterations for the termination criterion. & $\begin{array}{l}\text { Obtained by the complexity of the problem to be } \\
\text { optimized, in coupling with other PSO parameters }(D, N) .\end{array}$ \\
$\begin{array}{l}k_{f} \text { is the value of iterations for which the relative improvement of the } \\
\text { objective function satisfies the convergence check. }\end{array}$ & $\begin{array}{l}\text { If the relative enhancing of the objective function over } \\
\text { the last } k_{f} \text { iterations (containing the current iteration) is } \\
\begin{array}{l}f_{m} \text { is minimum relative to enhancing the number of the objective } \\
\text { function. }\end{array}\end{array}$ \\
\hline
\end{tabular}

and predicted values. We implemented the PSO algorithm using MATLAB. Every swarm present in the PSO algorithm contained the $F_{1}, F_{2}$, and $F_{3}$ coefficients. The obtained values of the unknown coefficients were used in the proposed damage frequency correlation ratio to decrease the errors in estimating the correlation factor of the damage frequency values. Figure 14 shows the flowchart of the proposed damage frequency correlation ratio, which was used to improve the accuracy of the correlation factor of damage frequency prediction. This chart shows the major structure of the correlation factor of the damage frequency.

The PSO algorithm can be implemented to search for the optimum correlation factor of the damage frequency of a communication tower through the following steps:

- The swarm is initialized by assigning a random position in the problem hyperspace to each particle;

- The objective function of the proposed damage frequency correlation ratio for each particle is evaluated;

- The objective function value of each individual particle is obtained by comparing the current value with its. If the current value is better than its, the present particle position, $X_{i}$, is set as pbest ${ }_{i}$;
- The particle with the best objective function value is identified. The value of its objective function is determined as gbest, and its position is gbest $_{i}$;

- The positions and velocities of all the particles are updated using Eqns (5) and (6);

- Steps 2 to 5 are reiterated until the convergence criteria are satisfied (when the maximum number of iterations or a sufficiently good objective function value is reached).

\subsection{Construction of the proposed PSO algorithm}

A correlation factor, which is a simple procedure, was used to identify the relationship between the frequencies under healthy and damaged conditions of UHPFRC communication towers using PSO. Statistical analysis methods, including the coefficient of variation $(\mathrm{CoV})$ and correlation coefficient $(R)$ analysis, were used in this study to evaluate or test the frequency correlation factor for a damaged UHPFRC communication tower. The mean square error (MSE) objective function was used in this study.

The amount of data utilized to build a particular model can adversely affect the accuracy of the final model. The

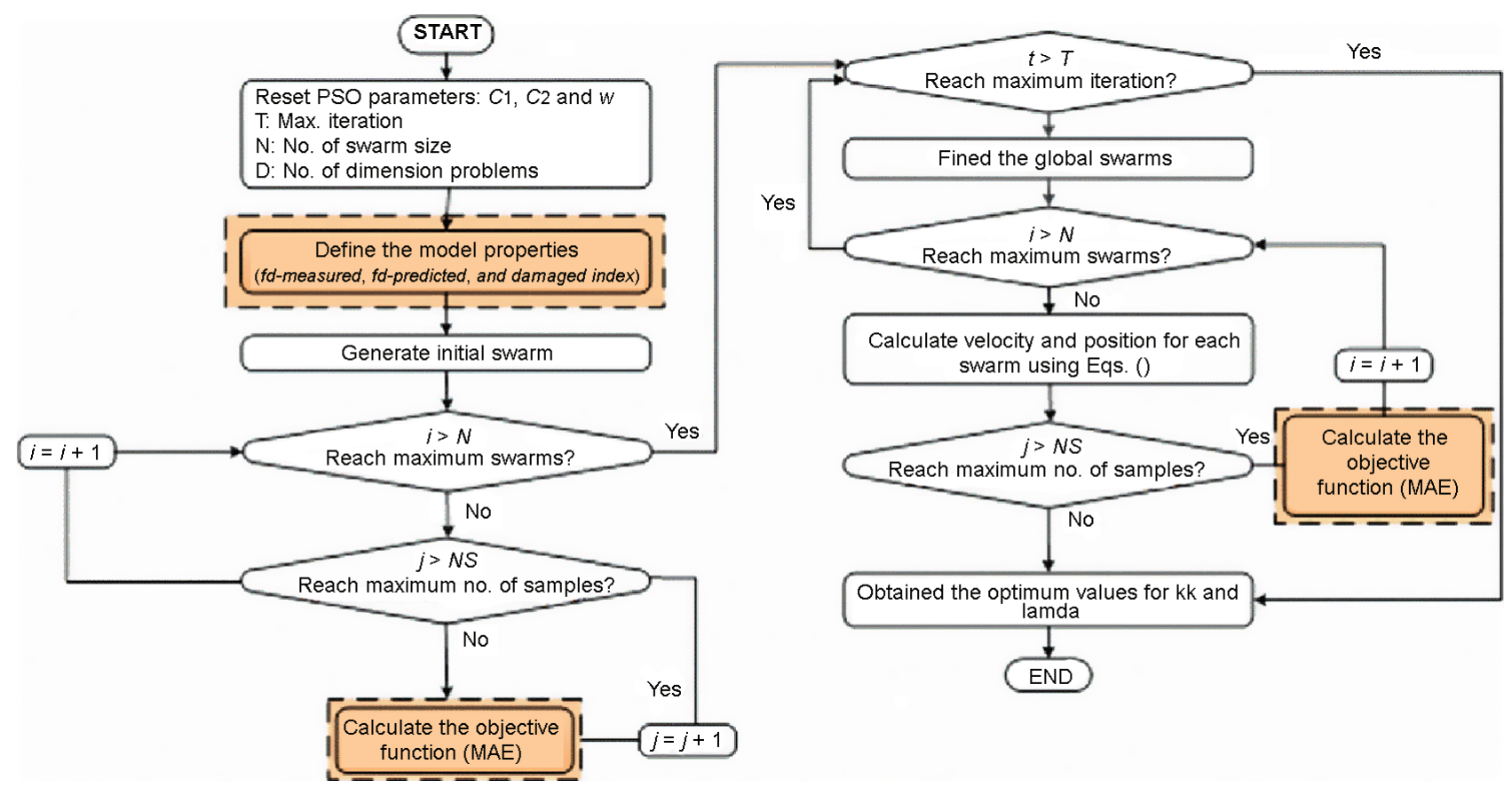

Figure 14. Flowchart of hybrid PSO for calculating correlation factor of the frequency of damage communication tower 
minimum ratio of swarm sizes is estimated from the number of objects over the number of selected variables. Model acceptability was originally suggested by Frank and Todeschini (1994). They further suggested that five swarms will be safer than three swarms. In the current research, this ratio was considerably higher, with a value of $60 / 2$, which is equal to 30 swarms.

The values of $c_{1}=c_{2}=1.494$ (cognitive and social acceleration factors) and $w=0.7$ (initial inertia weight) were suggested by Lavanya and Udgata (2011) to achieve rapid convergence. These values were used in the current investigation.

The process involved in the PSO algorithm is updated until a predefined number of maximum iterations is reached or a suitable gbest is generated. In this study, the number of iterations was estimated to be 5000 because of the variation in the objective functions that becomes constant after 2800 iterations. Five swarm sizes (10, 20, 30, 40, and 50) were investigated to enable the PSO algorithm to select suitable swarms that can minimize the elapsed time and error. The PSO algorithm was tested for the PSO parameters, and the following objective functions of MSE were obtained for 10, 20, 30, 40, and 50 swarms. Figure 15 illustrates that 30 swarms yield the best solution in the algorithm, which indicates the minimum objective functions of 0.00261 for MSE. On one hand, as warm size of 30 yields more optimum results in terms of computation time and accuracy based on the pre-analysis result of different swarm sizes

On the other hand, swarm sizes of 10 and 20 exhibited high error rates, and swarm sizes of 40 and 50 required longer analysis times than that of a swarm size of 30, which achieved a minimum objective function. The optimum values for the unknown coefficients $F_{1}, F_{2}$, and $F_{3}$ obtained from the algorithm are presented in Table 4 , and are applied in the proposed damage frequency correlation ratio. In accordance with a logical hypothesis introduced by Smith and Shust (2004), when the correlation coefficient (Figure 16) of a model exceeds 0.8 , a strong correlation exists between the predicted frequency by the PSO algorithm and the estimated frequency value by FEM. Figure 15 shows that the proposed damage frequency correlation ratio with a high $R(0.871)$ value predicted the target values with an acceptable accuracy degree.

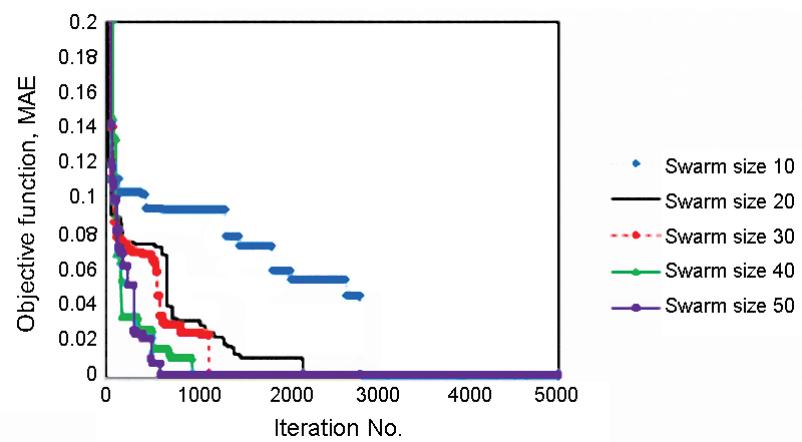

Figure 15. Convergence process for different swarm sizes

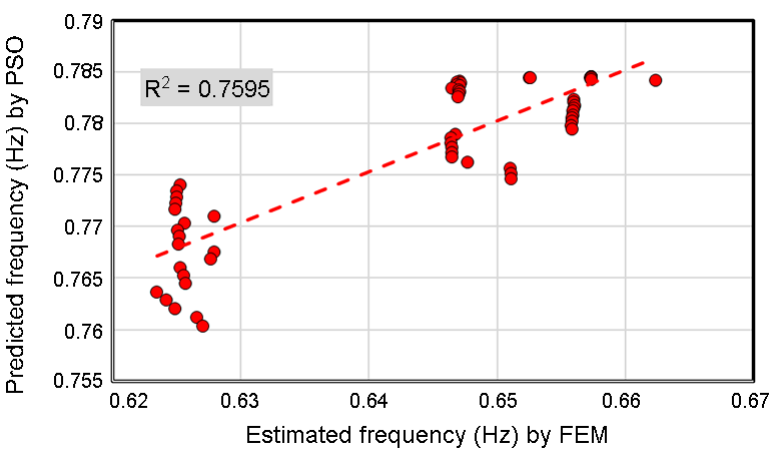

Figure 16. Estimated frequency by FEM vs. predicted frequency by PSO correlation factor for the frequency of damage UHFPRC communication tower

Table 4. Parameters used in the PSO algorithm setting

\begin{tabular}{|lc|}
\hline Factor & Value \\
\hline$F_{1}$ & $-8.3757 \times 10^{-6}$ \\
$F_{2}$ & $7.4987 \times 10^{-5}$ \\
$F_{3}$ & 0.8378 \\
Iteration & 5000 \\
Upper bound & 1 \\
Lower bound & -1 \\
\hline
\end{tabular}

The proposed damage frequency correlation ratio that predicts the damage frequency of a UHPFRC communication tower using PSO is given by the following Eqn:

$$
\begin{aligned}
f_{\text {damage }}= & \left(\left(-8.3757 \times 10^{-6} \times D I^{2}\right)+(7.4987 \times\right. \\
& \left.\left.10^{-5} \times D I\right)+0.8378\right) \times f_{\text {healthy }},
\end{aligned}
$$

where $f_{\text {damage }}$ - damage frequency of the tower; $f_{\text {healthy }}-$ healthy frequency of the tower; DI - damage index.

\section{Verification of the proposed damage frequency correlation ratio with case studies}

The FEM for the $30 \mathrm{~m}$ tall communication tower determined the frequency response that was produced to build the PSO algorithm for developing the damage correlation factor. Two case studies were considered to validate the proposed damage frequency correlation ratio.

\subsection{Case study 1}

A $15 \mathrm{~m}$ tall communication tower was constructed to validate the proposed damage frequency correlation ratio for the correlation factor of frequency of the damaged UHPFRC communication tower. Figure 17 shows the comparisons of the damage frequency correlation ratio $f_{d}$ predicted using PSO and the damage frequency correlation ratio $f_{\text {damage }}$ estimated through FEM with the damage index, which consists of 60 types of damage, there by proving that the proposed damage frequency correla- 
tion ratio is generally trustworthy. Previous studies have showed that a $\mathrm{CoV}$ value below $10 \%$ indicates high accuracy as reported by Gomes (2000), whereas CoV values between $20 \%$ and $30 \%$ signify low accuracy, and values above $30 \%$ represent low precision. In this study, the $\mathrm{CoV}$ values were $0.94 \%, 0.95 \%$, and $1.12 \%$ for the first three vibration modes, thereby indicating that the predicted results of the proposed damage frequency correlation ratio exhibit high accuracy and consistency. The mean value achieved in the proposed damage frequency correlation ratio of the correlation factor of the frequency of the damaged UHPFRC communication tower is close to 1.0 (1.1), which indicates good correlation between the estimated and measured frequencies of the damaged communication tower. Therefore, the proposed damage frequency correlation ratio efficiently estimated the frequency of the damaged communication tower, by considering different geometries and material properties.

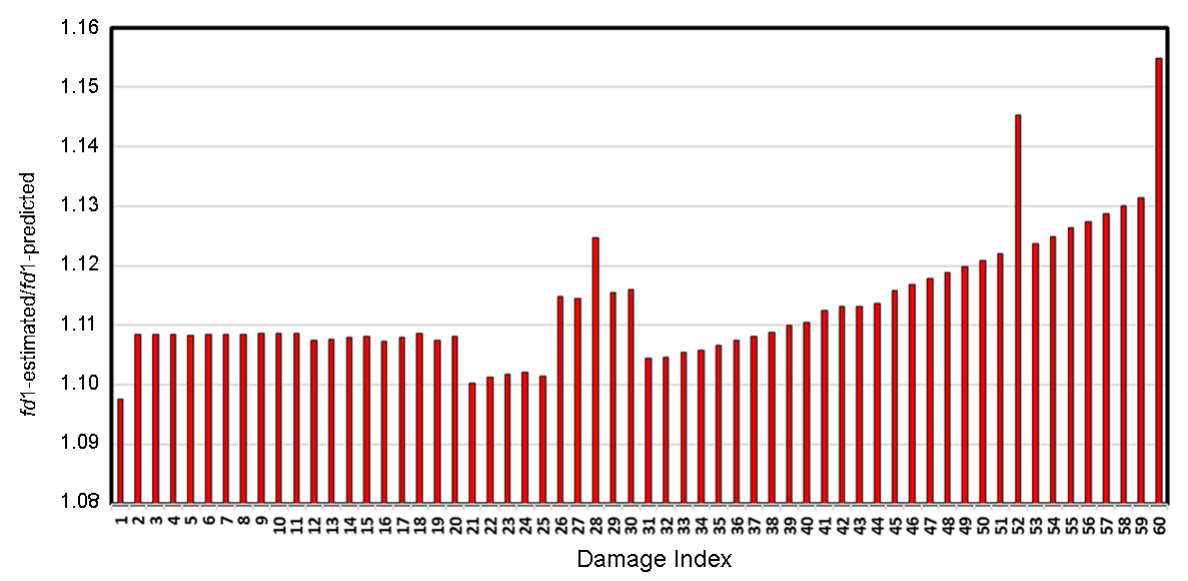

(a) Predictions and estimated of frequency for damaged communication tower for the first mode

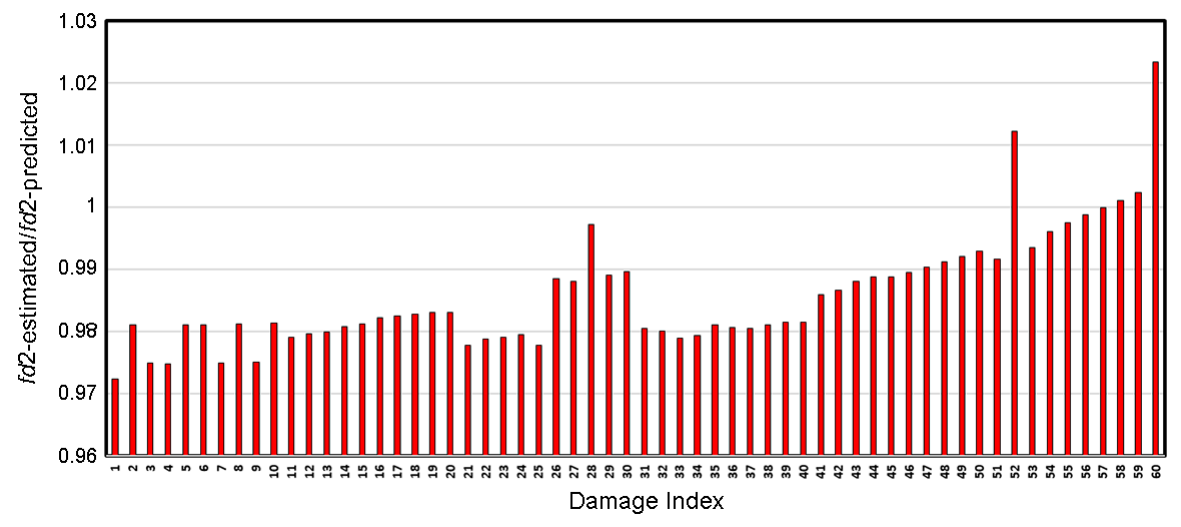

(b) Predictions and estimated of frequency for damaged communication tower for the second mode

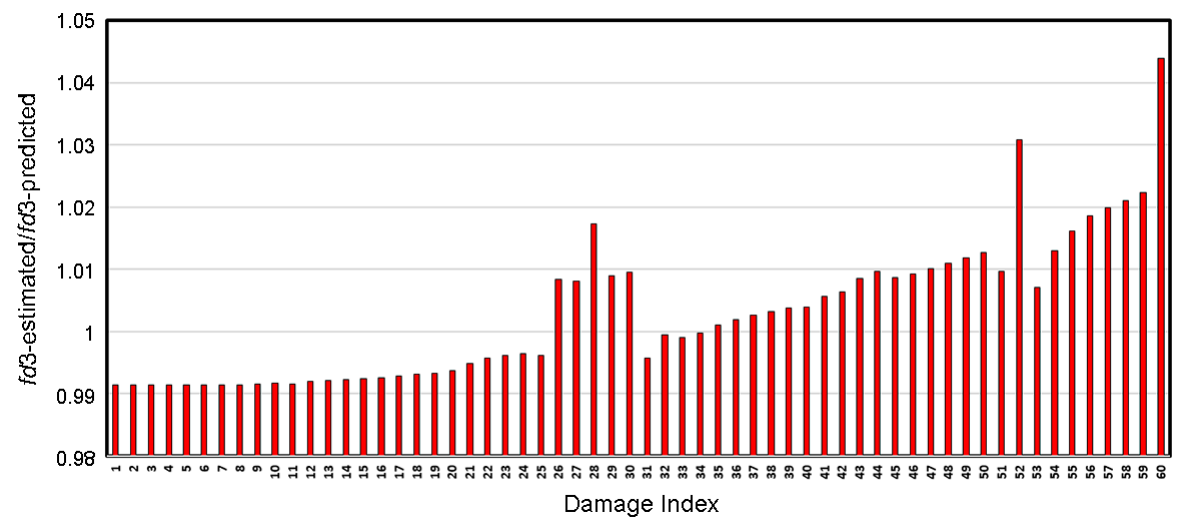

(c) Predictions and estimated of frequency for damaged communication tower for the third mode

Figure 17. Comparisons between the predictions and measured of frequency for tower damaged with $15 \mathrm{~m}$ height 


\subsection{Case study 2}

Another communication tower with a height of $45 \mathrm{~m}$ was simulated using FEM to verify the proposed damage frequency correlation ratio for the correlation factor of the frequency of the damaged UHPFRC communication tower. Figure 18 displays the comparison of the $f_{\text {damage }}$ predicted using PSO and $f_{\text {damage }}$ measured through FEM with the damage index, which consists of 60 types of damage. The proposed damage frequency correlation ratio achieved reliable and trustworthy results because the mean values of the MSE and root MSE are significantly near 1.0. The coefficients of variation obtained from the results of the proposed damage frequency correlation ratio are $3.8 \%, 1.7 \%$, and $0.98 \%$, which indicate the good accuracy and consistency of the obtained values. The results were sufficient to consider the proposed damage frequency correlation ratio in properly assessing the frequency of the damaged communication tower. Moreover, further research is necessary to improve the accuracy level of the proposed damage frequency correlation ratio for the correlation factor of the frequency of the damaged UHPFRC communication tower.

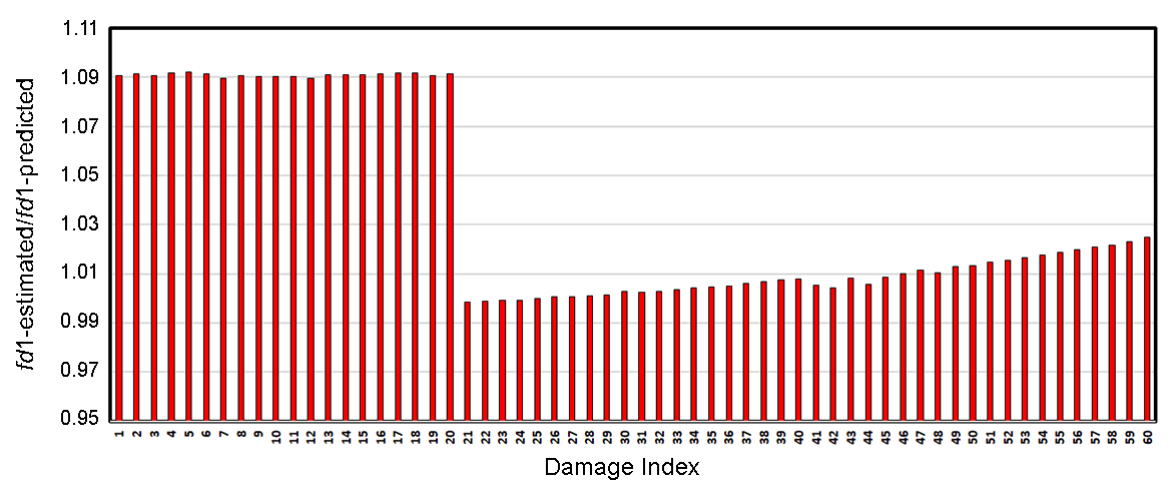

(a) Predictions and estimated of frequency for damaged communication tower for the first mode

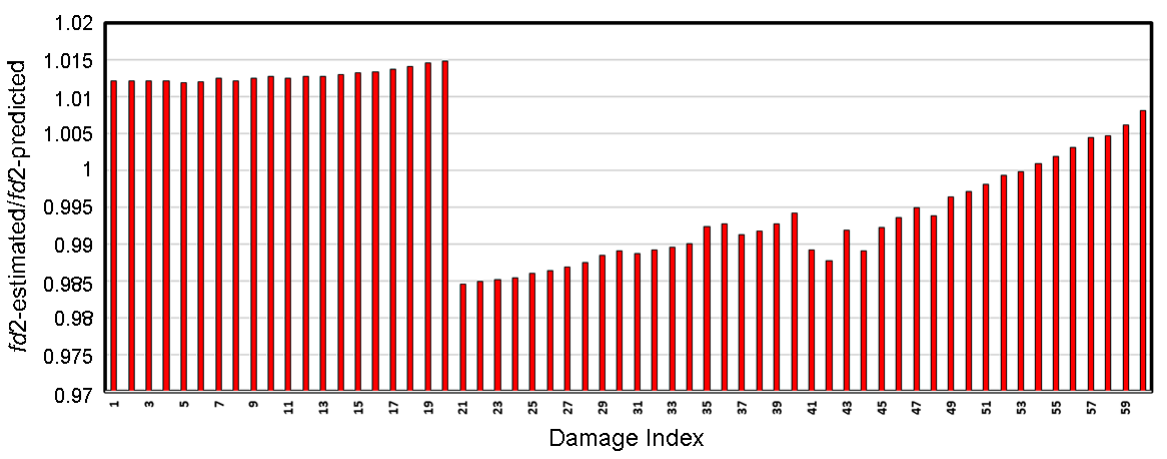

(b) Predictions and estimated of frequency for damaged communication tower for the second mode

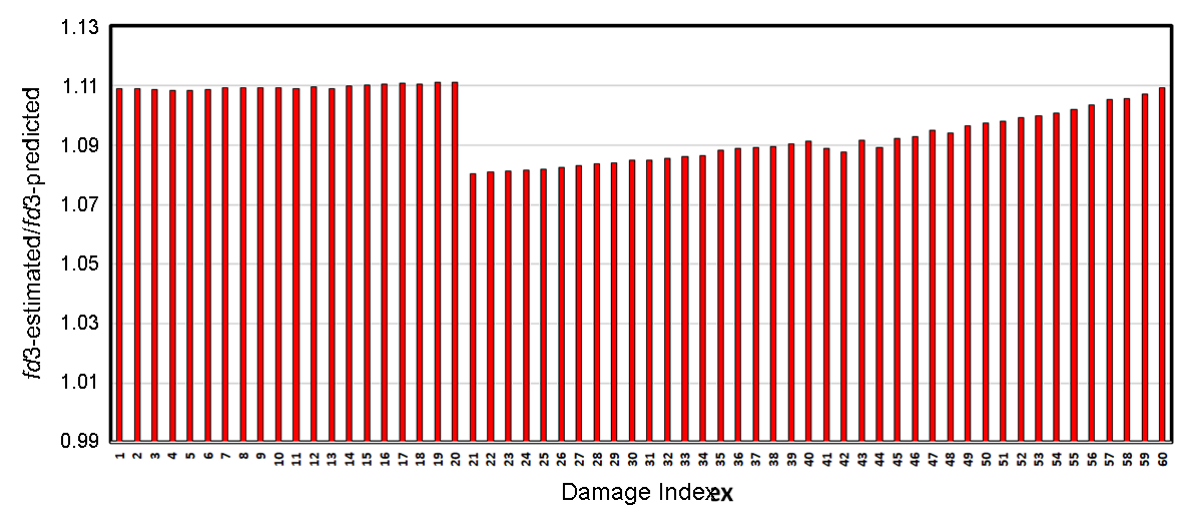

(c) Predictions and estimated of frequency for damaged communication tower for the third mode

Figure 18. Comparisons between the predictions and measured of frequency for a damaged tower with a $45 \mathrm{~m}$ height 


\section{Conclusions}

This study proposed a correlation factor for identifying the relationship between frequencies underhealthy and damaged states of various UHPFRC communication towers under different configurations using PSO. FEM was implemented to predict the behavior of a communication tower under healthy and damaged conditions through a dynamic frequency that contributed to building and testing the PSO algorithm. Three communication towers with heights of $15 \mathrm{~m}, 30 \mathrm{~m}$, and $45 \mathrm{~m}$ were considered to develop the frequency correlation factor. The tower with a height of 30m was tested experimentally to verify the results and develop the PSO algorithm for the damage correlation, whereas the towers with the heights of $15 \mathrm{~m}$ and $45 \mathrm{~m}$ were used to validate the algorithm.

On the basis of the results of the preceding case studies, the following conclusions were drawn:

- The maximum variation in the frequencies obtained from FEM and the experimental results was 5.8\% for a UHPFRC communication tower.

- The first natural frequency considerably changed compared with the other natural frequencies after damage occurred. The changes in frequency after damage depended on the span, geometry, and level of damage suffered by the structure. The variation in low frequencies due to damage formation in the tower is more evident than that in high frequencies, which exhibits less variation, and identifying the changes in frequencies for different types and locations of damage can be complicated.

- The damage frequency correlation ratio was based on the data collected from three simulated FEMs of communication towers.

- A wide range of datasets with a total of 540 from the three simulated FEMs of the communication towers was used to build and verify the correlation factor of the damage frequency of a tower. The statistical analysis showed that the $C o V$, mean, and $R$ values achieved good accuracy and consistency with the obtained values. Therefore, the correlation factor can be widely used to predict the damage frequency of communication towers.

- The $15 \mathrm{~m}$-tall tower presented CoV values of $0.94 \%$, $0.95 \%$, and $1.12 \%$ for the first three modes, thereby indicating that the predicted results of the proposed damage frequency correlation ratio exhibited high accuracy and consistency. Meanwhile, the $45 \mathrm{~m}$ tall tower presented $\mathrm{CoV}$ values of approximately $3.8 \%$, $1.7 \%$, and $0.98 \%$ for the first three modes, which indicates good correlation between the measured and estimated damage frequencies of the communication tower obtained using the proposed damage frequency correlation ratio.

\section{Acknowledgements}

This research receives support from Dura Technology Sdn. Bhd. and Dr. Voo Yen Lai, under a research project from Ministry of Science Technology \& Innovation, Malaysia, entitled "Development and construction of Internet Transmission Tower Using Ultra High-Performance Concrete". Their help and support are gratefully acknowledged.

\section{Author contributions}

Authors made substantial contributions to acquisition of data and analysis and interpretation of data; participated in drafting the article; and gave final approval of the version to be submitted and any revised version.

\section{Funding}

This work was supported by the Dura Technology Sdn. Bhd through Dr. Voo Yen Lai under Research Project from Mosti (Ministry of Science Technology \& Innovation).

\section{Disclosure statement}

The authors declare that they have no relevant or material financial interests that relate to the research described in this paper.

\section{References}

Alaghebandha, M., Hajipour, V., \& Hemmati, M. (2017). Optimizing multi-objective sequencing problem in mixed-model assembly line on just-in-time: particle swarm optimization algorithm. International Journal of Management Science and Engineering Management, 12(4), 288-298. https://doi.org/10.1080/17509653.2016.1258593

Antunes, P., Travanca, R., Varum, H., \& André, P. (2012). Dynamic monitoring and numerical modelling of communication towers with FBG based accelerometers. Journal of Constructional Steel Research, 74, 58-62.

https://doi.org/10.1016/j.jcsr.2012.02.006

Ashour, A. F., \& Rishi, G. (2000). Tests of reinforced concrete continuous deep beams with web openings. ACI Structural Journal, 97(3), 418-426.

Begambre, O., \& Laier, J. E. (2009). A hybrid Particle Swarm Optimization-Simplex algorithm (PSOS) for structural damage identification. Advances in Engineering Software, 40(9), 883-891. https://doi.org/10.1016/j.advengsoft.2009.01.004

Chagwiza, G., Jones, B. C., Hove-Musekwa, S. D., \& Mtisi, S. (2018). A new hybrid matheuristic optimization algorithm for solving design and network engineering problems. International Journal of Management Science and Engineering Management, 13(1), 11-19. https://doi.org/10.1080/17509653.2016.1269136

Dassault Systèmes Simulia Corp. (2014). ABAQUS standard user's manual. Version 6. RI, USA: Providence,. RI, USA.

Dong, R., Xu, J., \& Lin, B. (2017). ROI-based study on impact factors of distributed PV projects by LSSVM-PSO. Energy, 124, 336-349. https://doi.org/10.1016/j.energy.2017.02.056

Dua, R., Watkins, S. E., Wunsch, D. C., Chandrashekhara, K., \& Akhavan, F. (2001, July). Detection and classification of impact-induced damage in composite plates using neural networks. In Proceedings of the International Joint Conference on Neural Networks (IJCNN'01), 15-19 July 2001, Washington, DC, USA. https://doi.org/10.1109/IJCNN.2001.939106 
Eberhart, R., \& Kennedy, J. (1995, October). A new optimizer using particle swarm theory. In Proceedings of the Sixth International Symposium on the Micro Machine and Human Science (MHS'95), 4-6 October 1995, Nagoya, Japan. https://doi.org/10.1109/MHS.1995.494215

European Committee for Standardization (CEN). (2005). EN 1991-1-4, Eurocode 1: Actions on structures, part 1-4: general actions - wind actions.

European Committee for Standardization (CEN). (2006). EN 1993-3-1, Eurocode 3: Design of steel structures, part 3-1: towers, masts and chimneys - towers and masts.

Frank, I. E., \& Todeschini, R. (1994). The data analysis handbook. Vol. 14. Amsterdam, Netherlands: Elsevier.

Gomes, F. P. (2000). Experimental statistics. Piracicaba: FEALQ (in Portuguese).

Grünbaum, C. (2008). Structures of tall buildings (Rapport TVBK-5156). Lund: Lunds Tekniska Högskola.

Guidorzi, R., Diversi, R., Vincenzi, L., Mazzotti, C., \& Simioli, V. (2014). Structural monitoring of a tower by means of MEMSbased sensing and enhanced autoregressive models. European Journal of Control, 20(1), 4-13. https://doi.org/10.1016/j.ejcon.2013.06.004

Hanoon, A. N., Jaafar, M. S., Hejazi, F., \& Abdul Aziz, F. N. (2017a). Strut-and-tie model for externally bonded CFRPstrengthened reinforced concrete deep beams based on particle swarm optimization algorithm: CFRP debonding and rupture. Construction and Building Materials, 147, 428-447. https://doi.org/10.1016/j.conbuildmat.2017.04.094

Hanoon, A. N., Jaafar, M. S., Hejazi, F., \& Abdul Aziz, F. N. (2017b). Energy absorption evaluation of reinforced concrete beams under various loading rates based on particle swarm optimization technique. Engineering Optimization, 49(9), 1483-1501. https://doi.org/10.1080/0305215X.2016.1256729

Joint Technical Committee. (2002). AS/NZS 1170.2 Structural design actions, Part 2: wind actions. Australian/New Zealand Standard. Sydney: Standards Australia International Ltd and Wellington: Standards New Zealand.

Kaveh, A., \& Zolghadr, A. (2015). An improved CSS for damage detection of truss structures using changes in natural frequencies and mode shapes. Advances in Engineering Software, 80, 93-100. https://doi.org/10.1016/j.advengsoft.2014.09.010

Kazemi, M. A., Nazari, F., Karimi, M., Baghalian, S., Rahbarikahjogh, M. A., \& Khodabandelou, A. M. (2011, April). Detection of multiple cracks in beams using particle swarm optimization and artificial neural network. In The $4^{\text {th }}$ International Conference on Modeling, Simulation and Applied Optimization (ICMSAO), 19-21 April 2011, Kuala Lumpur, Malaysia. https://doi.org/10.1109/ICMSAO.2011.5775595

Kessler, S. S., Spearing, S. M., Atalla, M. J., Cesnik, C. E. S., \& Soutis, C. (2002). Damage detection in composite materials using frequency response methods. Composites Part B: Engineering, 33(1), 87-95. https://doi.org/10.1016/S1359-8368(01)00050-6

Kim, J-T., \& Stubbs, N. (2002). Improved damage identification method based on modal information. Journal of Sound and Vibration, 252(2), 223-238. https://doi.org/10.1006/jsvi.2001.3749

Kulkarni, R. V., \& Venayagamoorthy, G. K. (2011). Particle swarm optimization in wireless-sensor networks: A brief survey. IEEE Transactions on Systems, Man, and Cybernetics, Part C (Applications and Reviews), 41(2), 262-267.

https://doi.org/10.1109/TSMCC.2010.2054080
Lavanya, D., \& Udgata, S. K. (2011). Swarm intelligence based localization in wireless sensor networks. In the International Workshop on Multi-disciplinary Trends in Artificial Intelligence. https://doi.org/10.1007/978-3-642-25725-4_28

Majumdar, A., Nanda, B., Maiti, D. K., \& Maity, D. (2014). Structural damage detection based on modal parameters using continuous ant colony optimization. Advances in Civil Engineering, Article ID 174185. https://doi.org/10.1155/2014/174185

Mhaske, M. S., \& Shelke, R. S. (2015). Detection of depth and location of crack in a beam by vibration measurement and its comparative validation in ANN and GA. International Engineering Research Journal (IERJ), Special Issue 2, 488-493.

Negm, H. M., \& Maalawi, K. Y. (2000). Structural design optimization of wind turbine towers. Computers \& Structures, 74 (6), 649-666. https://doi.org/10.1016/S0045-7949(99)00079-6

Nhamage, I. A., Lopez, R. H., \& Miguel, L. F. F. (2016). An improved hybrid optimization algorithm for vibration baseddamage detection. Advances in Engineering Software, 93, 4764. https://doi.org/10.1016/j.advengsoft.2015.12.003

Oros Gmbh. (2006). 3-Series/NVGate reference manual.

Paultre, P., Weber, B., Mousseau, S., \& Proulx, J. (2016). Detection and prediction of seismic damage to a high-strength concrete moment resisting frame structure. Engineering Structures, 114, 209-225.

https://doi.org/10.1016/j.engstruct.2016.02.013

Rardin, R. L. (1998). Optimization in operations research. New York: Prentice Hall.

Ren, W.-X., \& De Roeck, G. (2002). Structural damage identification using modal data. II: Test verification. Journal of Structural Engineering, 128(1), 96-104. https://doi.org/10.1061/(ASCE)0733-9445(2002)128:1(96)

Saisi, A., Gentile, C., \& Guidobaldi, M. (2015). Post-earthquake continuous dynamic monitoring of the Gabbia Tower in Mantua, Italy. Construction and Building Materials, 81, 101-112. https://doi.org/10.1016/j.conbuildmat.2015.02.010

Shi, Y., \& Eberhart, R. (1998). A modified particle swarm optimizer. In Proceedings of the IEEE International Conference on the Evolutionary Computation, IEEE World Congress on Computational Intelligence, 4-9 May 1998, Anchorage, AK, USA. https://doi.org/10.1109/ICEC.1998.699146

Sinou, J.-J. (2009). A review of damage detection and health monitoring of mechanical systems from changes in the measurement of linear and non-linear vibrations. Nova Science Publishers, Inc.

Smith, K. B., \& Shust, W. C. (2004). Bounding natural frequencies in structures I: Gross geometry, material and boundary conditions. In Proceedings of the XXII International Modal Analysis Conference, Society of Experimental Mechanics.

Sutar, M. K. (2012). Finite element analysis of a cracked cantilever beam. International Journal of Advanced Engineering Research and Studies, 1(2), 285-289.

Xie, F., Wang, Q-j., \& Li, G-l. (2012). Optimization research of FOC based on PSO of induction motors. In $15^{\text {th }}$ International Conference on Electrical Machines and Systems (ICEMS), 2124 October 2012, Sapporo, Japan.

Yang, X. F., Swamidas, A. S. J., \& Seshadri, R. (2001). Crack identification in vibrating beams using the energy method. Journal of Sound and Vibration, 244(2), 339-357. https://doi.org/10.1006/jsvi.2000.3498 


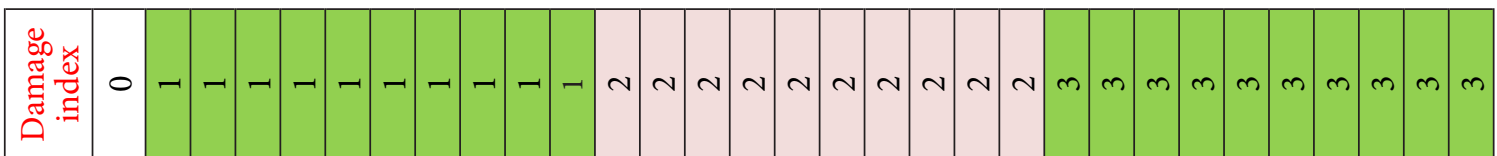

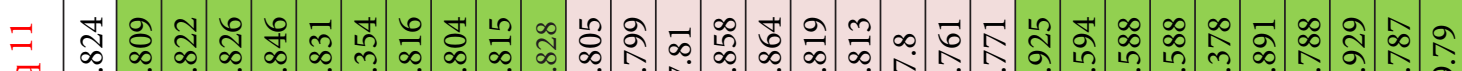

离

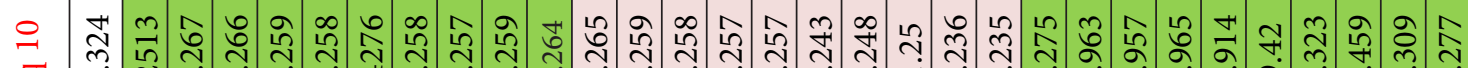

๖

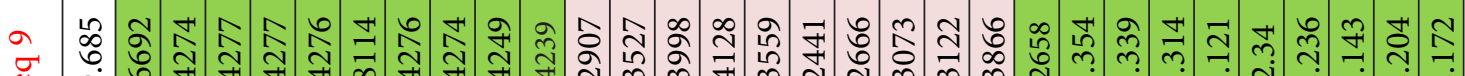

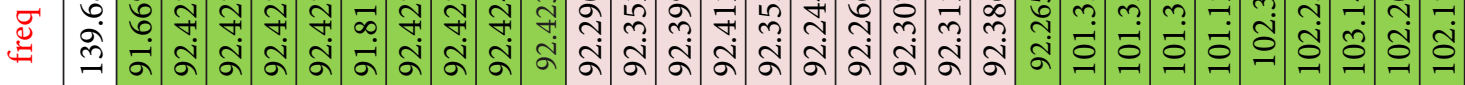

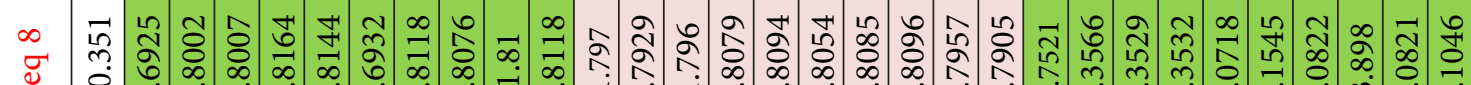

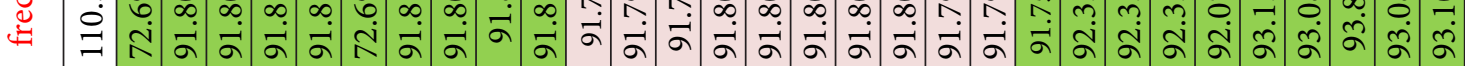

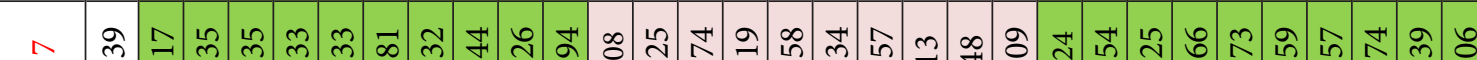
ન

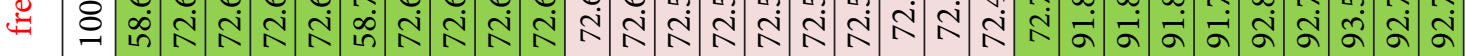

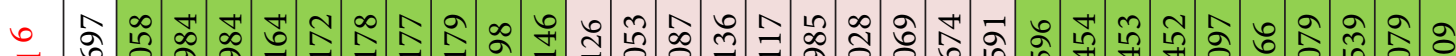
च

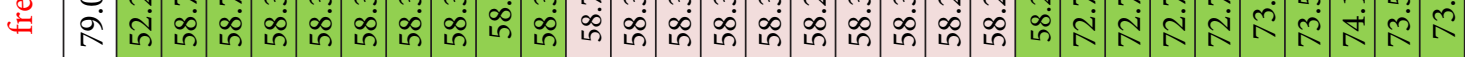

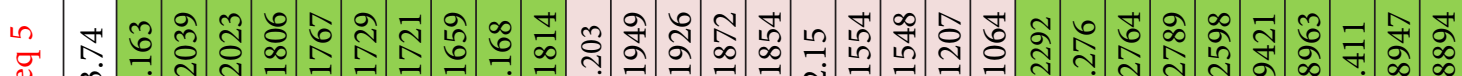

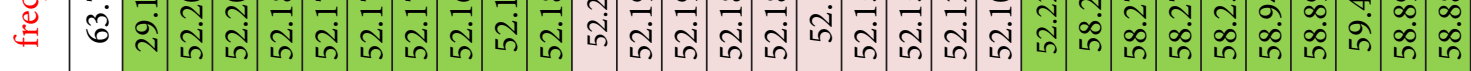
+ 水

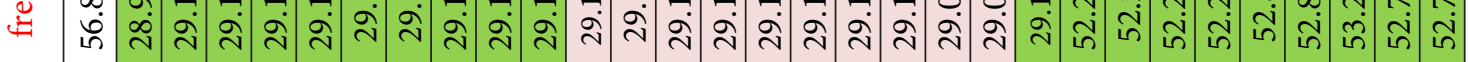
m f

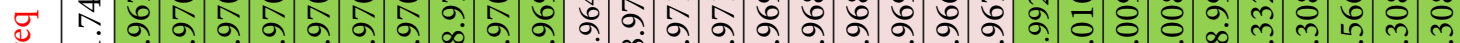

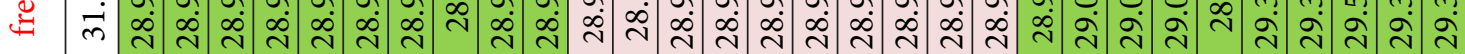

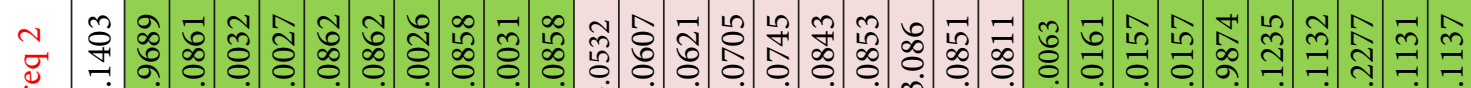

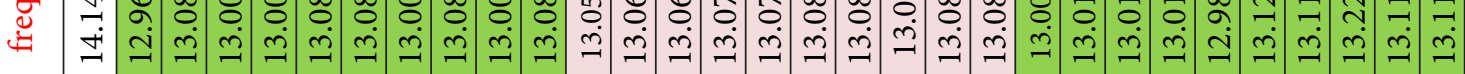

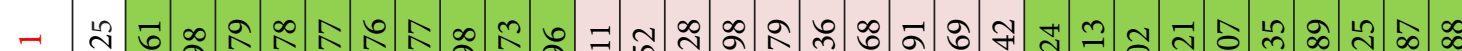
水

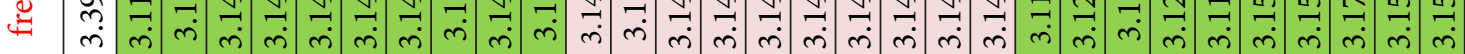

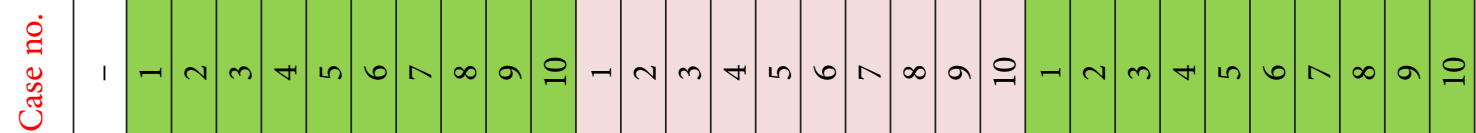

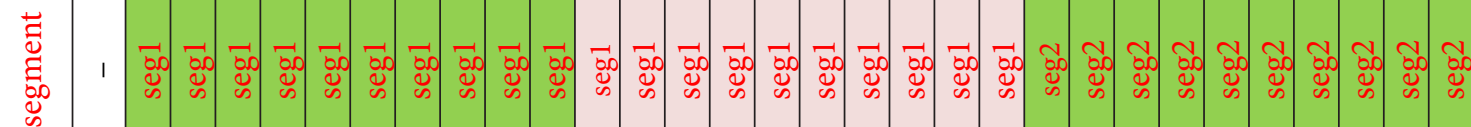




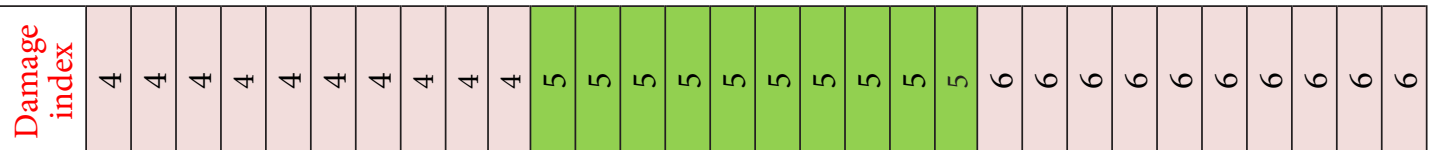

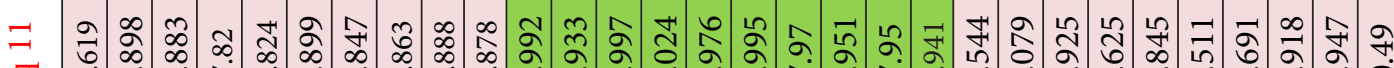

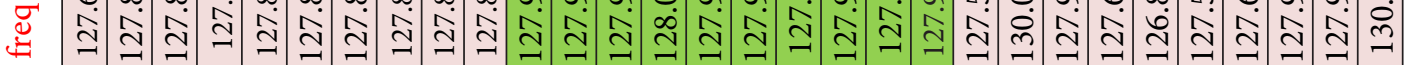

을

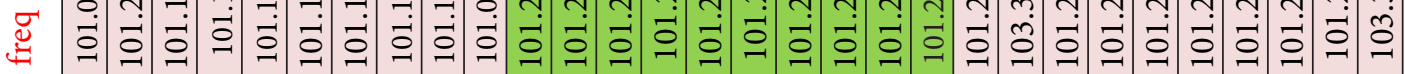

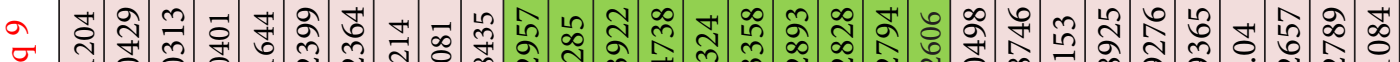
F ঊ

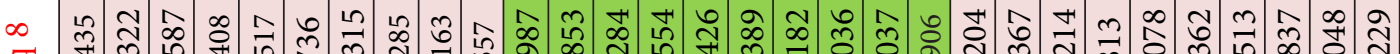

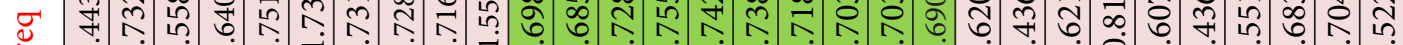

ঊ à ă

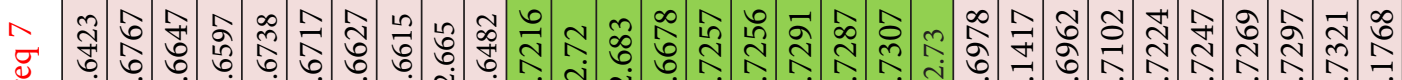

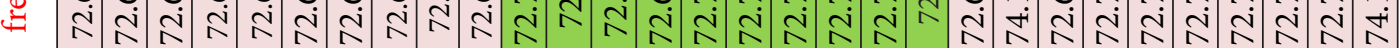

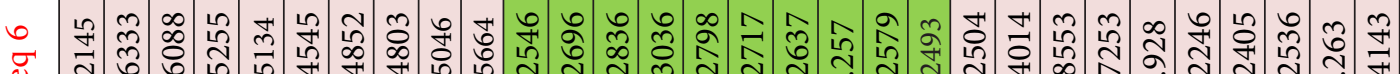

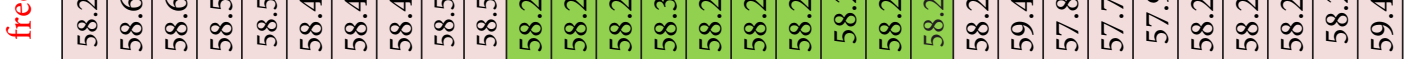

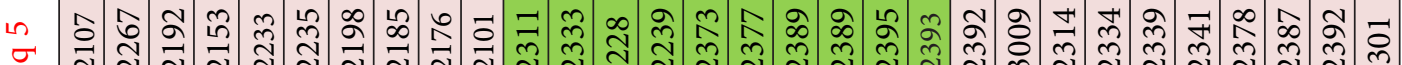

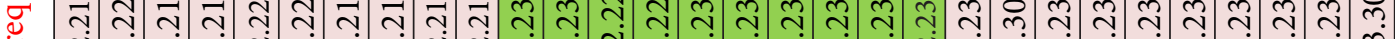

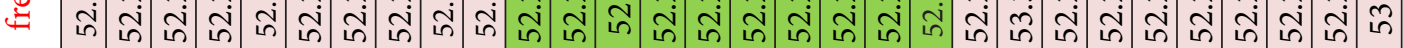

+ تூ

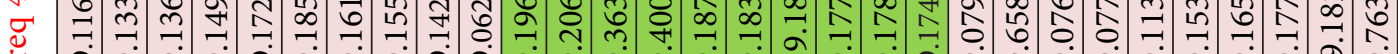

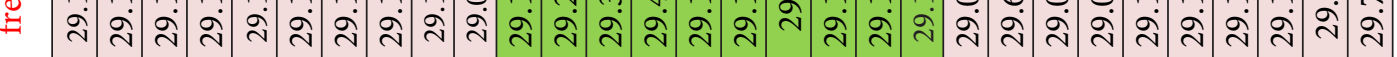

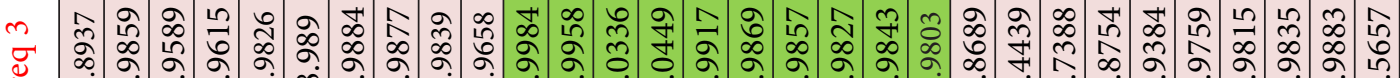

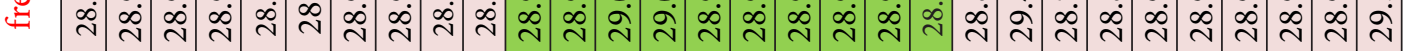

N

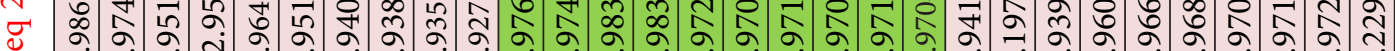

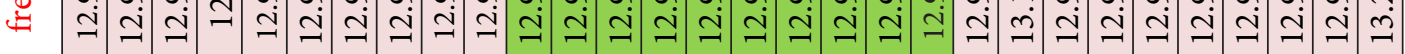

- ঢ

F

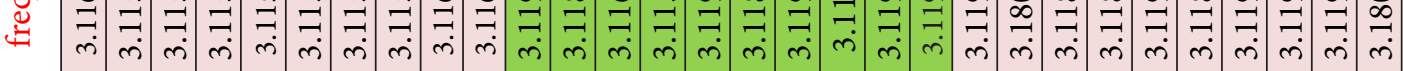

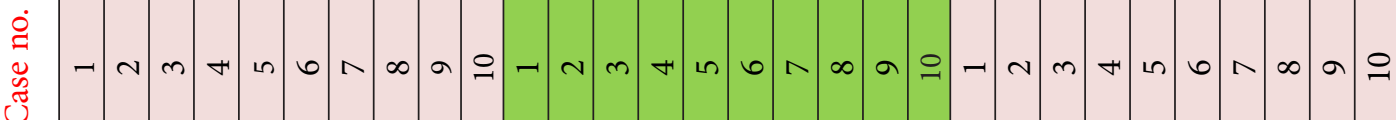

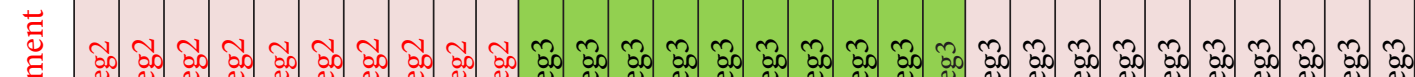

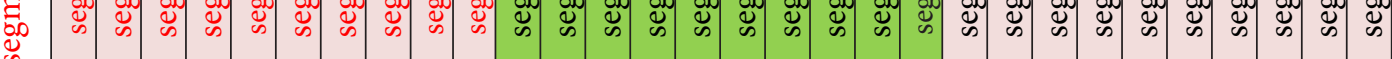

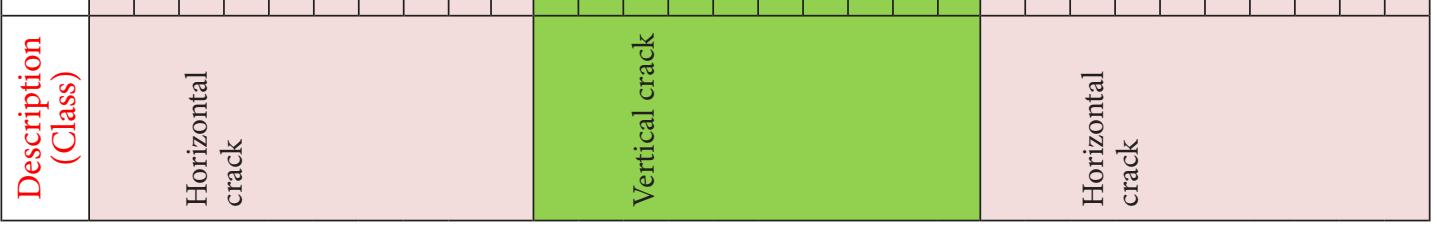




\begin{tabular}{|c|c|c|c|c|c|c|c|c|c|c|c|c|c|c|c|c|c|c|c|c|c|}
\hline & & & -1 & - & - & -7 & $-1-$ & -1. & $-N$ & & $\sim \sim$ & $\checkmark N$ & $\sim \sim N$ & $\sim|c|$ & $\sim m$ & $m$ & $m m a$ & $m|m| c$ & $m m$ & & $m$ \\
\hline G & $\hat{n}$ & $\left|\begin{array}{c}\Omega \\
\infty \\
\\
-\vec{b}\end{array}\right|$ & 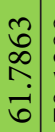 & & 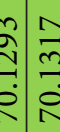 & $\left|\begin{array}{c}0 \\
\stackrel{0}{0} \\
\stackrel{0}{0} \\
م\end{array}\right|$ & $\begin{array}{l}\cong \\
\stackrel{2}{R} \\
\stackrel{2}{\circ}\end{array}$ & 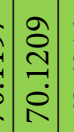 & 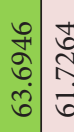 & $\begin{array}{l}+ \\
\stackrel{n}{n} \\
\vec{b}\end{array}$ & 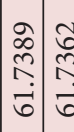 & 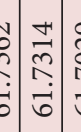 & 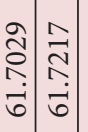 & 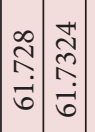 & 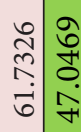 & 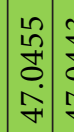 & 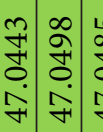 & 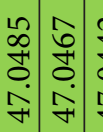 & 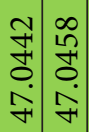 & & f \\
\hline I & $\mid \begin{array}{l}\infty \\
\infty \\
\stackrel{m}{=} \\
=\end{array}$ & 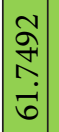 & $\begin{array}{l}\hat{\sigma} \\
\stackrel{1}{\leftarrow} \\
\dot{6}\end{array}$ & $\begin{array}{l}2 \\
\sigma \\
\infty \\
\dot{\sigma} \\
\vdots\end{array}$ & 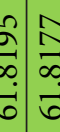 & $\left|\begin{array}{c}\hat{1} \\
\infty \\
\infty \\
\dot{\sigma}\end{array}\right|$ & 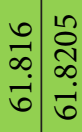 & 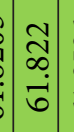 & \begin{tabular}{c|c}
$\infty$ & 0 \\
0 & 0 \\
0 & 0 \\
$\infty$ & 0 \\
$\vec{b}$ & \multicolumn{1}{|c|}{}
\end{tabular} & $\begin{array}{l}\vec{a} \\
\dot{b} \\
\dot{1}\end{array}$ & 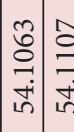 & 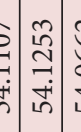 & 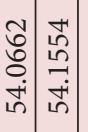 & 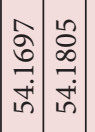 & 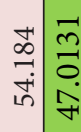 & 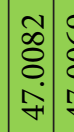 & 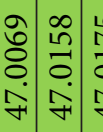 & 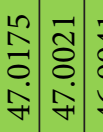 & 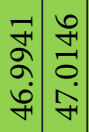 & $\mid \begin{array}{c}0 \\
0 \\
\dot{3} \\
f\end{array}$ & $\therefore$ \\
\hline g & 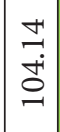 & $\begin{array}{c}0 \\
\vec{\sigma} \\
0 \\
\dot{f} \\
\end{array}$ & $\begin{array}{l}\overline{\hat{a}} \\
\dot{\sigma} \\
\dot{\gamma}\end{array}$ & 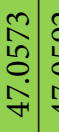 & 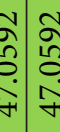 & 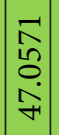 & 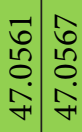 & $\begin{array}{c}\infty \\
0 \\
0 \\
0 \\
\dot{\gamma} \\
0\end{array}$ & 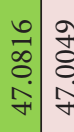 & 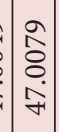 & 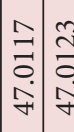 & 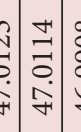 & 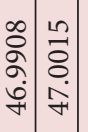 & 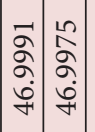 & 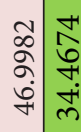 & $\begin{array}{c}2 \\
\hat{b} \\
+1 \\
\dot{m}\end{array}$ & 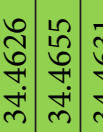 & 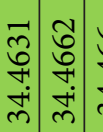 & 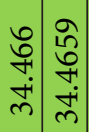 & 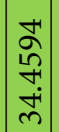 & \\
\hline \& & $\begin{array}{l}10 \\
\stackrel{1}{+} \\
\mathbb{1}\end{array}$ & $\begin{array}{l}\bar{\sigma} \\
\bar{\alpha} \\
\dot{\gamma}\end{array}$ & 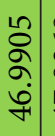 & 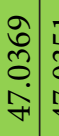 & 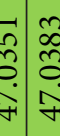 & $\mid \begin{array}{l}\overrightarrow{0} \\
\tilde{0} \\
\hat{x} \\
\hat{f}\end{array}$ & 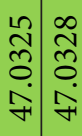 & 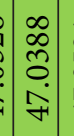 & 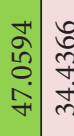 & $\begin{array}{c}\mathscr{O} \\
\tilde{\tilde{m}} \\
\dot{m} \\
\dot{m}\end{array}$ & 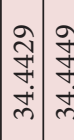 & 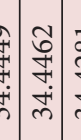 & 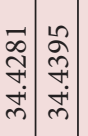 & 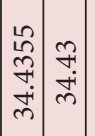 & 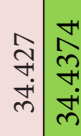 & 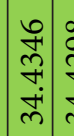 & 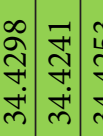 & 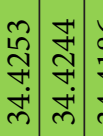 & 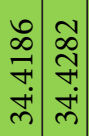 & & में \\
\hline ت्ञ & 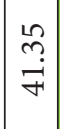 & $\begin{array}{c}\hat{m} \\
\stackrel{f}{f} \\
\dot{m}\end{array}$ & $\begin{array}{l}0 \\
\mathbb{F} \\
\dot{m} \\
\dot{m}\end{array}$ & 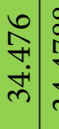 & 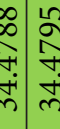 & $\mid \begin{array}{c}0 \\
\infty \\
7 \\
7 \\
\dot{m} \\
m\end{array}$ & 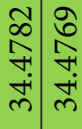 & $\begin{array}{l}1 \\
0 \\
7 \\
+1 \\
\dot{m}\end{array}$ & 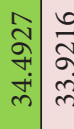 & 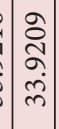 & 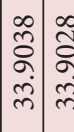 & 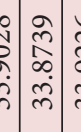 & 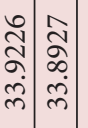 & 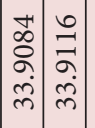 & 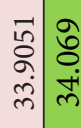 & $\begin{array}{c}\hat{\hat{\theta}} \\
\vdots \\
\dot{\mathrm{d}} \\
\mathbf{m}\end{array}$ & 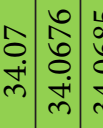 & 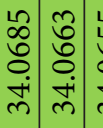 & 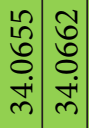 & $\mid \begin{array}{c}\vec{b} \\
0 \\
0 \\
\dot{m} \\
\dot{m}\end{array}$ & mं \\
\hline$\stackrel{\Xi}{\Xi}$ & $\overrightarrow{\dot{v}}$ & $\begin{array}{c}1 \\
\tilde{m} \\
\infty \\
0 \\
0 \\
\tilde{m} \\
\end{array}$ & 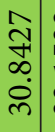 & $\begin{array}{ll}\tilde{n} & \\
& \\
m & m \\
m & \end{array}$ & $\begin{array}{l}\hat{c} \\
\vec{n} \\
\vec{n}\end{array}$ & $\mid \begin{array}{c}\vec{n} \\
\vec{m} \\
\stackrel{m}{n}\end{array}$ & 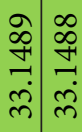 & $\begin{array}{c}\vec{a} \\
\vec{a} \\
\dot{m} \\
\tilde{m}\end{array}$ & & 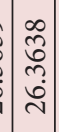 & 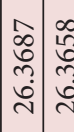 & 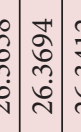 & 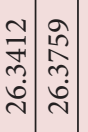 & 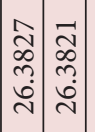 & 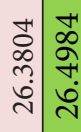 & 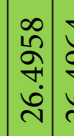 & 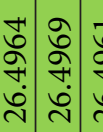 & 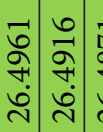 & 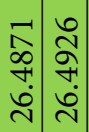 & 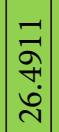 & 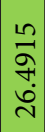 \\
\hline 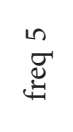 & $\begin{array}{l}\mathfrak{r} \\
\hat{2} \\
-1\end{array}$ & $\begin{array}{l}\overrightarrow{0} \\
0 \\
\tilde{n} \\
\tilde{n}\end{array}$ & $\mid \begin{array}{l}2 \\
\hat{\delta} \\
\tilde{m} \\
\\
\end{array}$ & $\begin{array}{l}\overrightarrow{\tilde{m}} \\
\overrightarrow{\tilde{n}} \\
\overrightarrow{\mathrm{n}}\end{array}$ & & 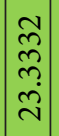 & 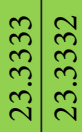 & $\begin{array}{c}\mid \\
\tilde{N} \\
\tilde{n} \\
\\
\end{array}$ & 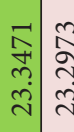 & 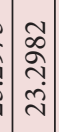 & 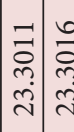 & 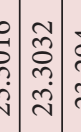 & 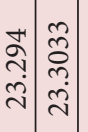 & 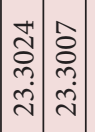 & 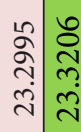 & $\begin{array}{l}\approx \\
\tilde{z} \\
\tilde{\sim} \\
\tilde{\lambda}\end{array}$ & 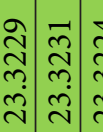 & 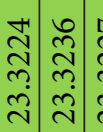 & 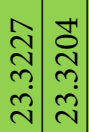 & & $\ddot{\sim}$ \\
\hline ஜ્⿹ & $\left|\begin{array}{l|}\infty \\
\infty \\
\infty\end{array}\right|$ & $\mid \begin{array}{c}\tilde{D} \\
\delta \\
\infty \\
\dot{\Xi} \\
\end{array}$ & $\begin{array}{ll}+ & 1 \\
\infty & 1 \\
\infty \\
\infty \\
\dot{y} & \vdots\end{array}$ & 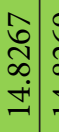 & 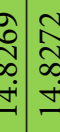 & 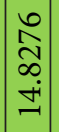 & 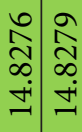 & $\begin{array}{l}\infty \\
\infty \\
\infty \\
\dot{\Xi} \\
- \\
-1\end{array}$ & 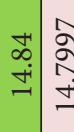 & \begin{tabular}{l}
2 \\
2 \\
2 \\
\hdashline \\
-1
\end{tabular} & 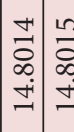 & 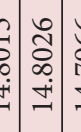 & 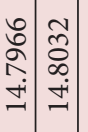 & 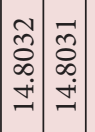 & 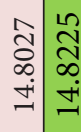 & 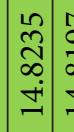 & 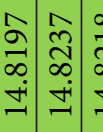 & 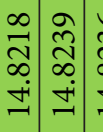 & 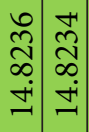 & $\left|\begin{array}{c}\vec{D} \\
\infty \\
\infty \\
\dot{ \pm} \\
-1\end{array}\right|$ & • \\
\hline$\ddot{\Xi}$ & \begin{tabular}{l|}
$\infty$ \\
$\dot{n}$
\end{tabular} & $\begin{array}{l}\infty \\
2 \\
\infty \\
\infty \\
\\
\end{array}$ & 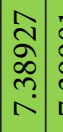 & $\begin{array}{l}\vec{\infty} \\
\stackrel{2}{a} \\
\stackrel{n}{n}\end{array}$ & 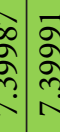 & 華 & 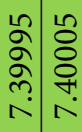 & 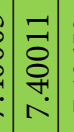 & 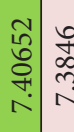 & 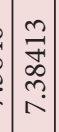 & 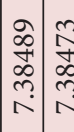 & 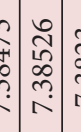 & 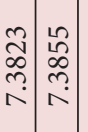 & 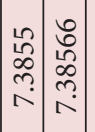 & & 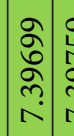 & 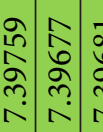 & 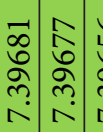 & 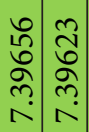 & & \\
\hline$\stackrel{\Xi}{\Xi}$ & $\mid \begin{array}{l}5 \\
0 \\
0\end{array}$ & 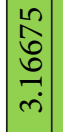 & 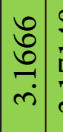 & 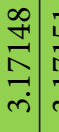 & $=\frac{5}{n}$ & 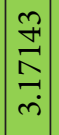 & 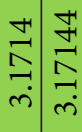 & 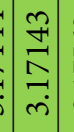 & 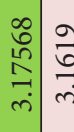 & 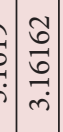 & 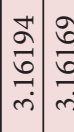 & 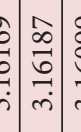 & 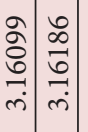 & \begin{tabular}{c|c}
$\bar{\sigma}$ & $\vec{\alpha}$ \\
$\vec{b}$ & $\vec{b}$ \\
$\dot{m}$ & $\vec{m}$ \\
$\dot{m}$
\end{tabular} & 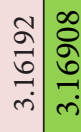 & 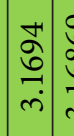 & 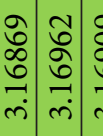 & 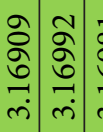 & 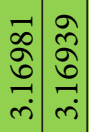 & & 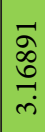 \\
\hline$\ddot{\Xi}$ & $\hat{\varrho}$ & $\mid \begin{array}{l}1 \\
\delta \\
6 \\
\infty \\
0 \\
0 \\
0\end{array}$ & $\mid \begin{array}{c}2 \\
\hat{b} \\
- \\
\infty \\
\hat{0} \\
0 \\
0\end{array}$ & 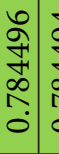 & 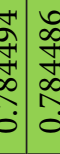 & 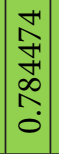 & 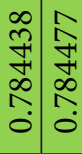 & 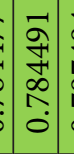 & 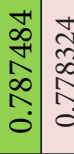 & 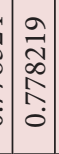 & 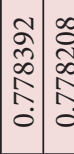 & 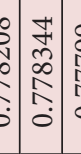 & 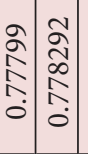 & 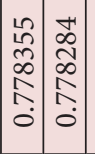 & 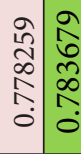 & 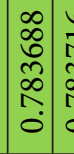 & 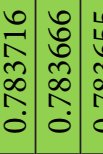 & 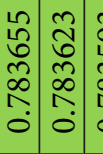 & 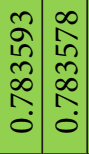 & $\begin{array}{c}\sqrt{n} \\
\underline{n} \\
\infty \\
\infty \\
\hat{0} \\
0\end{array}$ & $\mid \begin{array}{l}2 \\
\infty \\
\hat{0} \\
0\end{array}$ \\
\hline $\begin{array}{l}\text { J } \\
\text { D }\end{array}$ & I & - & $N$ & $m$ & + & 6 & $\wedge \infty$ & $a$ & 의 & $A N$ & 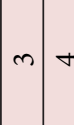 & t in & 6) & $\infty$\begin{tabular}{l|l}
$\infty$ & $\sigma$
\end{tabular} & 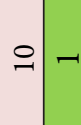 & $\sim \rho$ & $m+L$ & $\ln \mid 0$. & $\infty$ & $a$ & 으 \\
\hline Бू & & 它 & $\left|\begin{array}{|c|}\infty \\
\infty \\
\infty\end{array}\right|$ & $\stackrel{0}{\infty}$ & 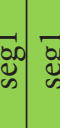 & . & 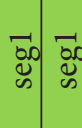 & $\begin{array}{l}30 \\
\infty \\
\infty\end{array}$ & $\begin{array}{l}0 \\
0 \\
0 \\
\infty\end{array}$ & | & 80 & 50 & \begin{tabular}{c|c|}
$\overrightarrow{b 00}$ & $\overrightarrow{0.0}$ \\
$\infty$ & 0 \\
$\infty$ & $\infty$
\end{tabular} & 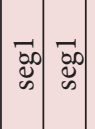 & $\begin{array}{l}\vec{b} \\
\dot{\infty} 0 \\
\infty\end{array}$ & $\left|\begin{array}{l}0 \\
0 \\
0 \\
\infty\end{array}\right|$ & $\begin{array}{lll}0 \\
0 \\
\infty\end{array}$ & $\begin{array}{lll}50 \\
\infty \\
\infty \\
\infty \\
\infty\end{array}$ & $\begin{array}{lll}20 \\
0 \\
\infty \\
\infty\end{array}$ & | & \\
\hline 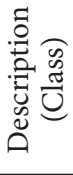 & 我 & & & & & & & & & & & 工 & & & & & & $=$ & & & \\
\hline
\end{tabular}




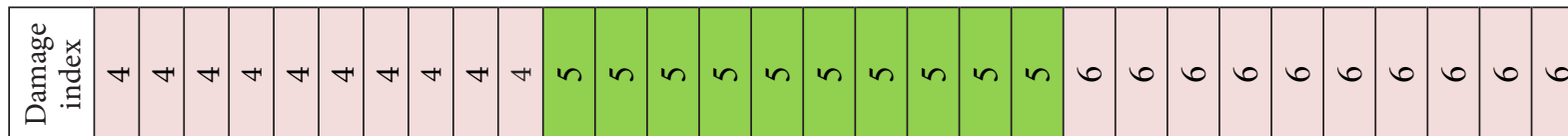

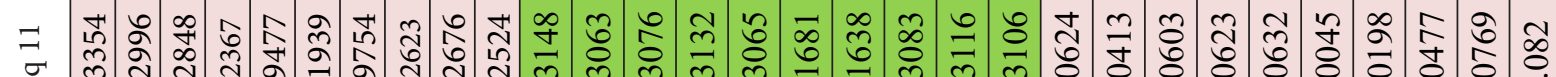

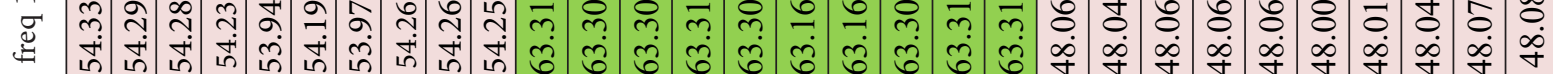

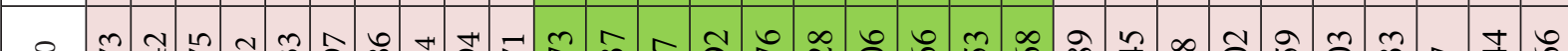

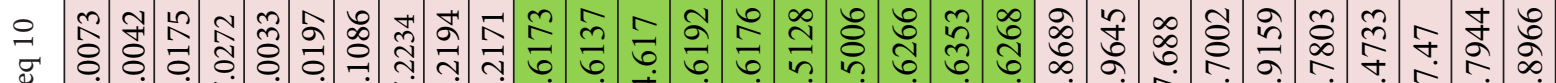

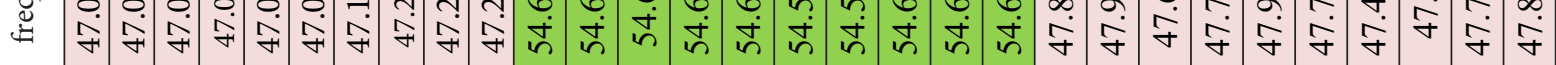

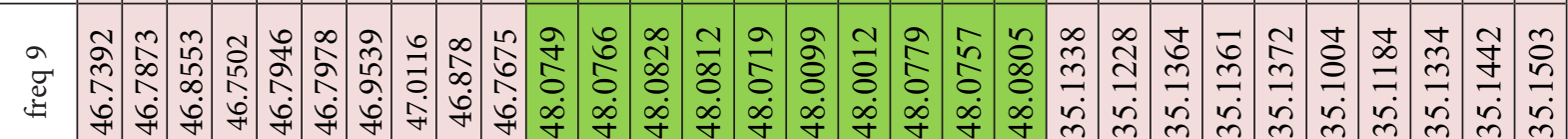
m

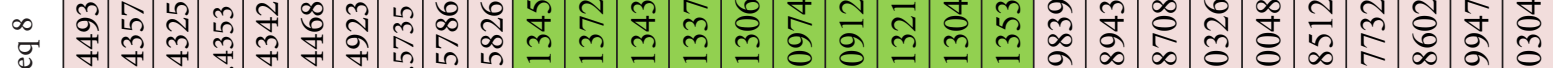

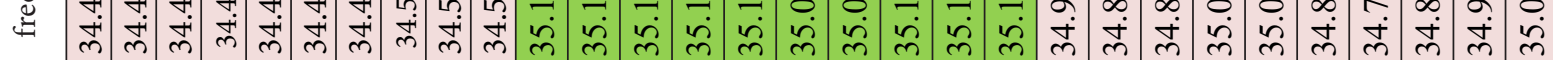

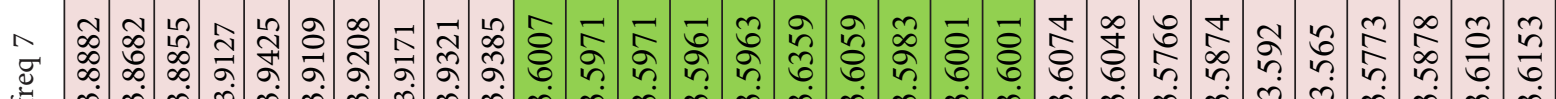

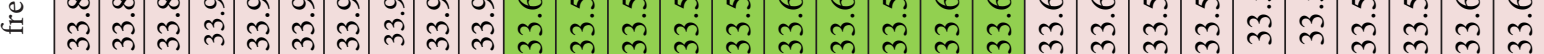

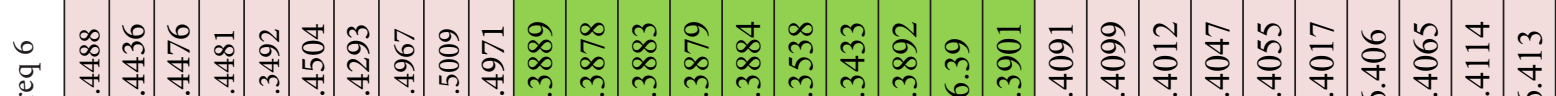

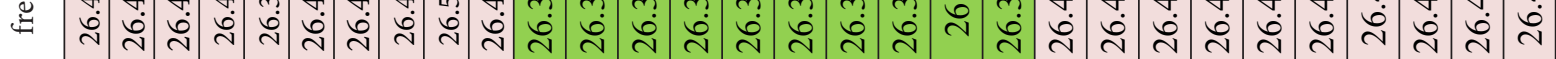

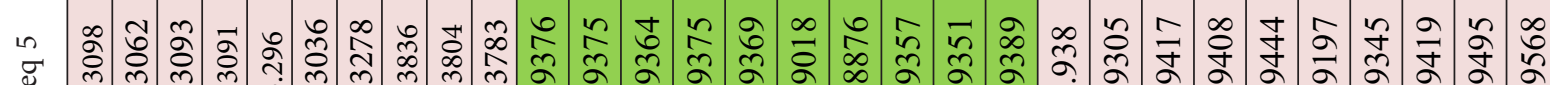

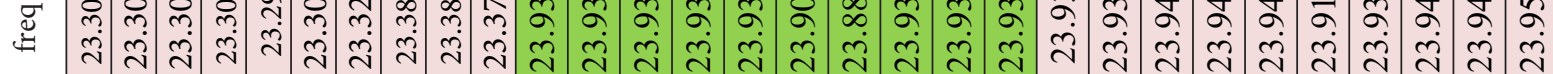

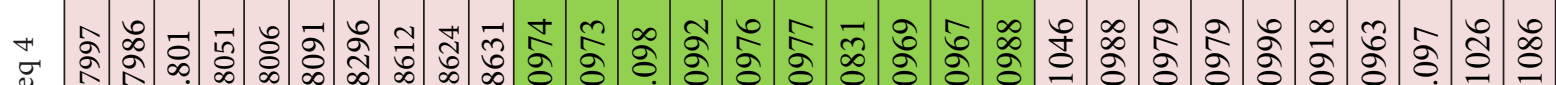

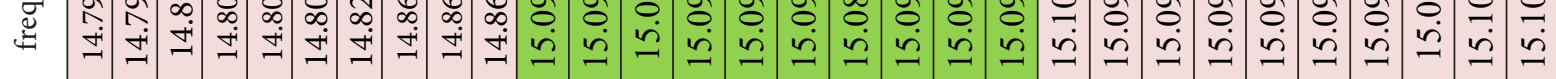

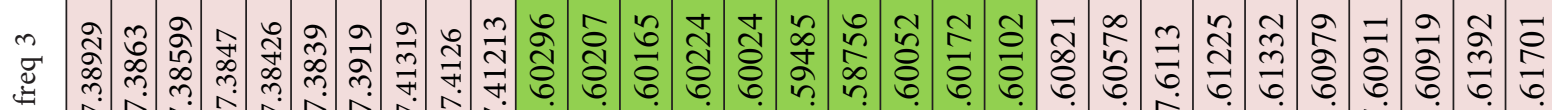

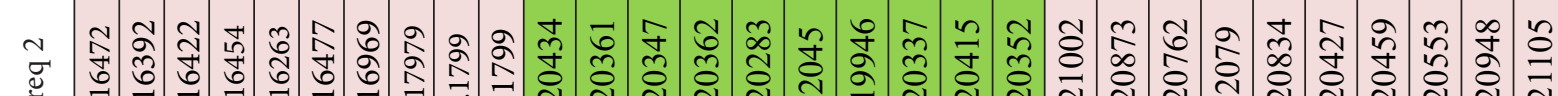

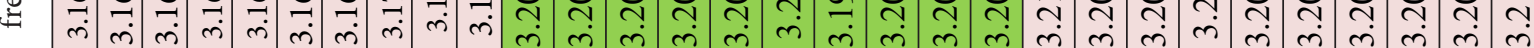

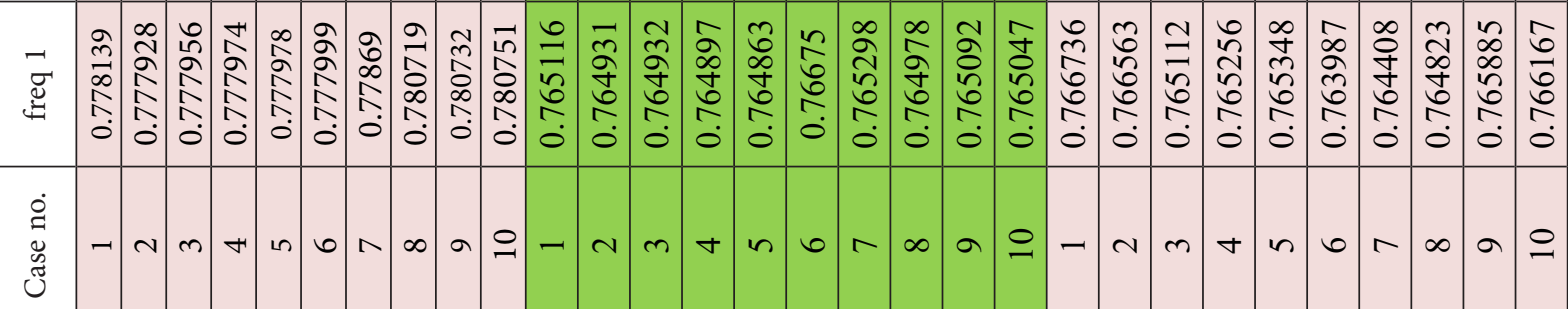

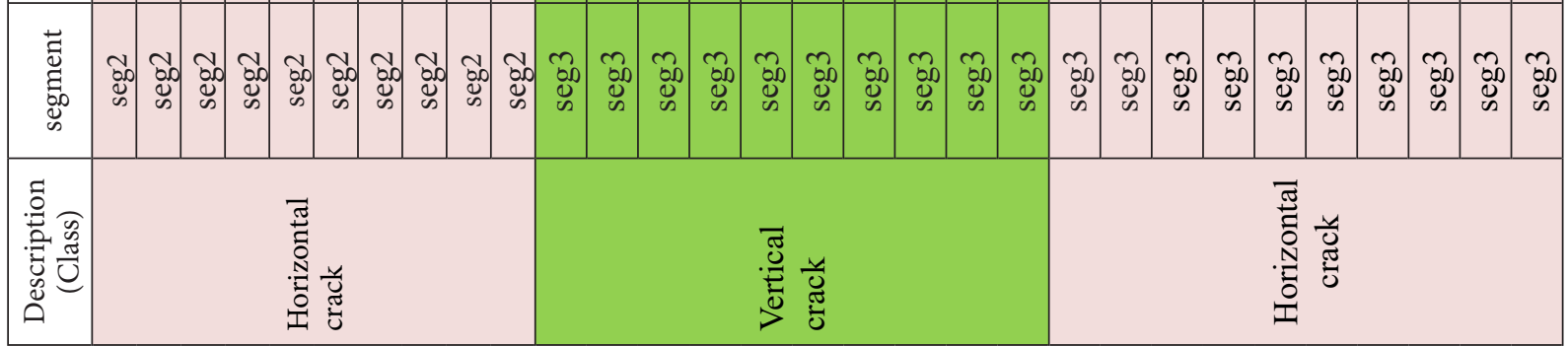




\begin{tabular}{|c|c|c|c|c|c|c|c|c|c|c|c|c|c|c|c|c|c|c|c|}
\hline. & & & -1 & $-1-$ & & $-1-$ & $4-1$ & -10 & \begin{tabular}{l|l}
4 \\
4
\end{tabular} & $\sim \sim$ & $\checkmark \sim$ & $\sim \sim$ & $\sim \sim \sim$ & & $m m$ & $n=m$ & $m m$ & $m m$ & $m$ \\
\hline す্ّ & $\mid \begin{array}{l}\hat{N} \\
\hat{N} \\
\hat{N} \\
+1 \\
i\end{array}$ & 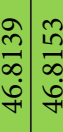 & 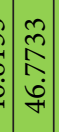 & & $\hat{\imath}$ & 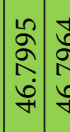 & 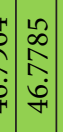 & 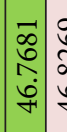 & 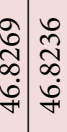 & 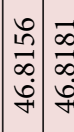 & 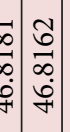 & 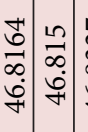 & 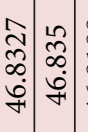 & 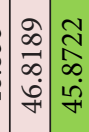 & 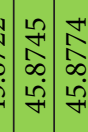 & 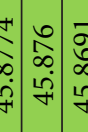 & 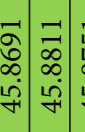 & 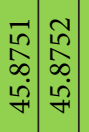 & \\
\hline$\underset{\Xi}{\breve{\Xi}}$ & 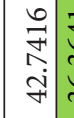 & & $\begin{array}{l}\vec{n} \\
\tilde{n} \\
\vdots \\
\vdots \\
\vdots \\
n\end{array}$ & & 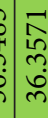 & 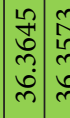 & 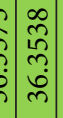 & 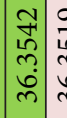 & 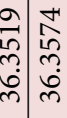 & & 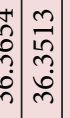 & 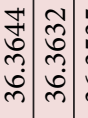 & 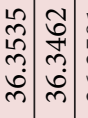 & & 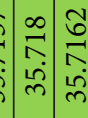 & 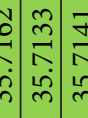 & 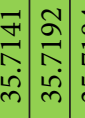 & 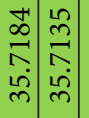 & \\
\hline$\underset{\Xi}{\mathscr{\Xi}}$ & 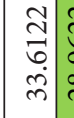 & & 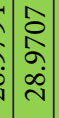 & & $\begin{array}{l}2 \\
\delta \\
\infty \\
\infty \\
\infty\end{array}$ & 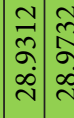 & $\begin{array}{l}0 \\
\vdots \\
\vdots \\
\vdots \\
\vdots\end{array}$ & & 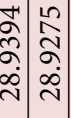 & 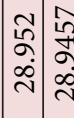 & 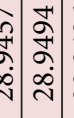 & 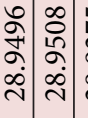 & 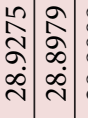 & 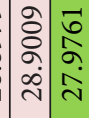 & 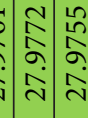 & 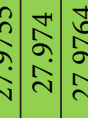 & 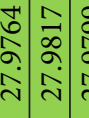 & 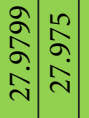 & \\
\hline$\ddot{\Xi}$ & 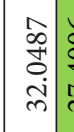 & & 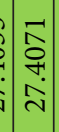 & & ì & 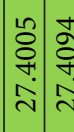 & 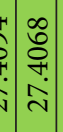 & & & 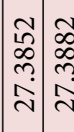 & 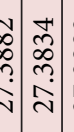 & 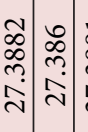 & 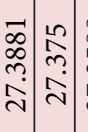 & 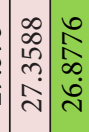 & 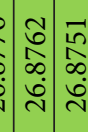 & 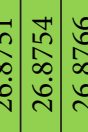 & 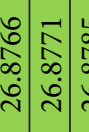 & 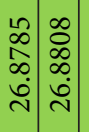 & \\
\hline$\underset{\Xi}{\mathscr{J}}$ & 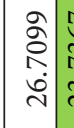 & & 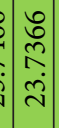 & & 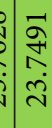 & & 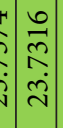 & 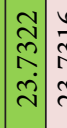 & 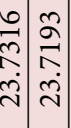 & & 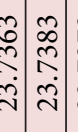 & & 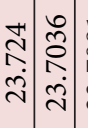 & 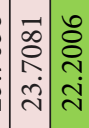 & 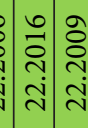 & 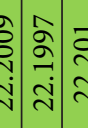 & 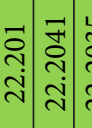 & 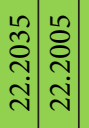 & \\
\hline ت्ञ & 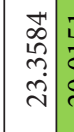 & & $\begin{array}{l}\vdots \\
\vdots \\
\vdots \\
\vdots \\
\vdots\end{array}$ & & 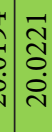 & 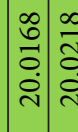 & 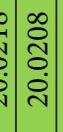 & \begin{tabular}{l|l}
$\hat{b}$ & 0 \\
0 & $\vdots$ \\
$\vdots$ & $\vdots$ \\
$\dot{\lambda}$ & $\vdots$ \\
$\vdots$
\end{tabular} & 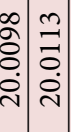 & 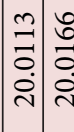 & 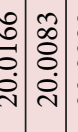 & 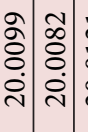 & 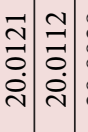 & 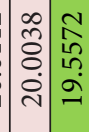 & 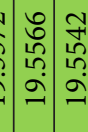 & 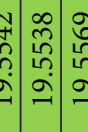 & 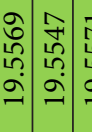 & 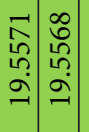 & 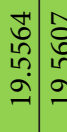 \\
\hline$\stackrel{\Xi}{\Xi}$ & $\left.\mid \begin{array}{c}m \\
= \\
\vdots \\
\vdots\end{array}\right]$ & & 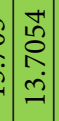 & & 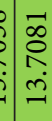 & $\begin{array}{lll} & \infty \\
\infty & \infty \\
0 & 0 \\
n & 0 \\
& n & \end{array}$ & 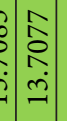 & 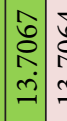 & & 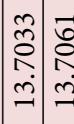 & 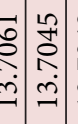 & 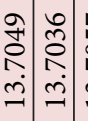 & 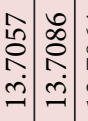 & 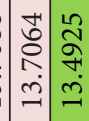 & 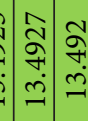 & 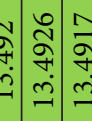 & 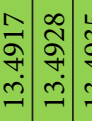 & 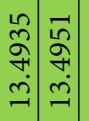 & 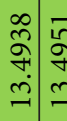 \\
\hline$\ddot{\Xi}$ & $\begin{array}{l}\tau \\
\delta \\
0 \\
0 \\
-\end{array}$ & 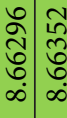 & 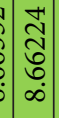 & & \begin{tabular}{l} 
Î \\
\multirow{J}{0}{} \\
$\stackrel{0}{0}$
\end{tabular} & \begin{tabular}{l|l} 
& 1 \\
$\infty$ & 0 \\
0 & 0 \\
0 & 0 \\
0 & 0 \\
$\infty$ & $\infty$ \\
$\infty$ & $\infty$
\end{tabular} & $\mid$ & 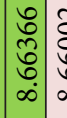 & 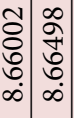 & 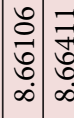 & 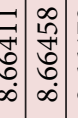 & 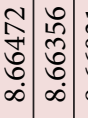 & 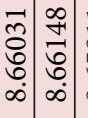 & 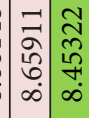 & 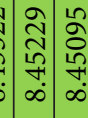 & 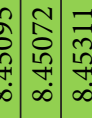 & 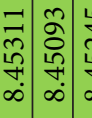 & 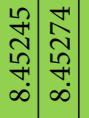 & \\
\hline$\stackrel{\Xi}{\varpi}$ & 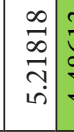 & 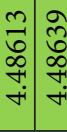 & 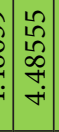 & 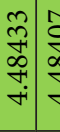 & . & 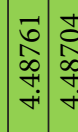 & 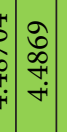 & 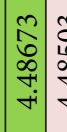 & 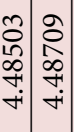 & 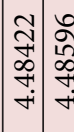 & 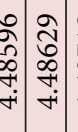 & 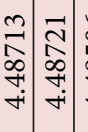 & 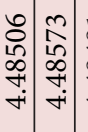 & 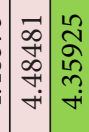 & 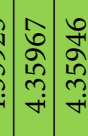 & 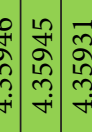 & 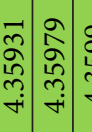 & 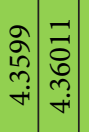 & 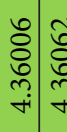 \\
\hline$\underset{\Xi}{\mathscr{U}}$ & 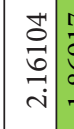 & 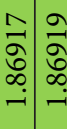 & 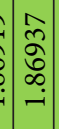 & 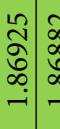 & ب. & 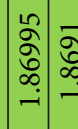 & 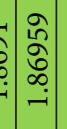 & 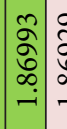 & 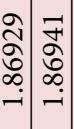 & 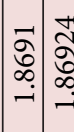 & 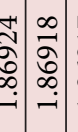 & 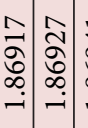 & 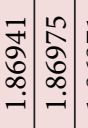 & 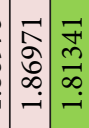 & 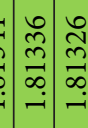 & 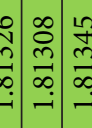 & 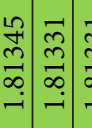 & 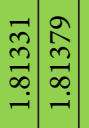 & \\
\hline ठृ & 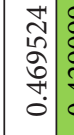 & 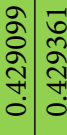 & 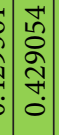 & & ఫิ & 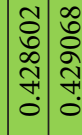 & 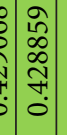 & 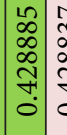 & 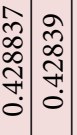 & 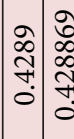 & 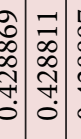 & 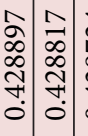 & 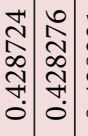 & 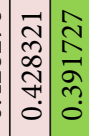 & 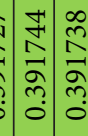 & 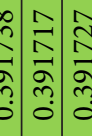 & 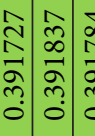 & 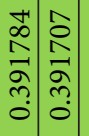 & 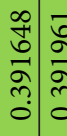 \\
\hline हु & I & 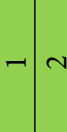 & & 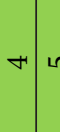 & 6 & $\infty$ & sol & 의 -1 & & $m \mid \nabla$ & + in & $0 . \wedge$ & $\infty$\begin{tabular}{l|l}
$\infty$ &
\end{tabular} & 의- & $\sim m$ & $n|r|$ in & in 0 & $\wedge \infty$ & o \\
\hline छ్ & 1 & ڤँ & 㐌 & $\stackrel{\infty}{\infty}$ & & 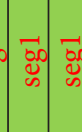 & t. & $\overbrace{0}^{\infty}$ & & $\varpi$ & 象 & $\begin{array}{c}\infty \\
\infty\end{array}$ & $\begin{array}{l}0 \\
0 \\
\infty \\
\infty\end{array}$ & 0 & 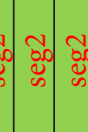 & 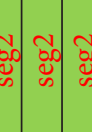 & 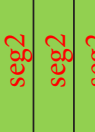 & $\begin{array}{lll}\infty & \infty \\
\infty & \infty \\
\infty\end{array}$ & ठ \\
\hline $\begin{array}{c}\tilde{E} \\
\tilde{D}\end{array}$ & 至 & & & & & & & & & & & & & & & & 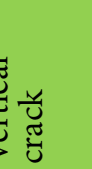 & & \\
\hline
\end{tabular}




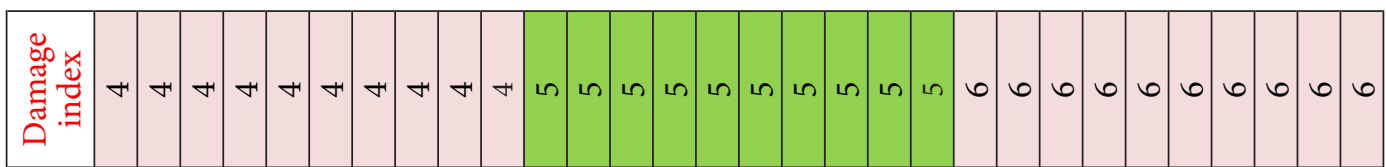

$\Rightarrow$ ก

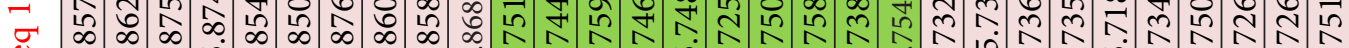

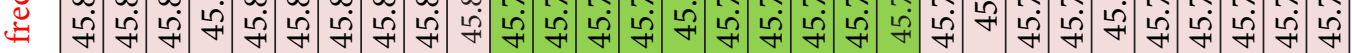

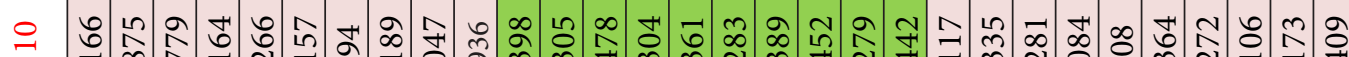

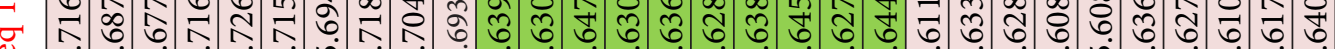

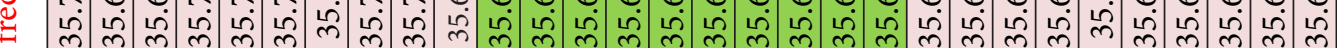

a ปิก

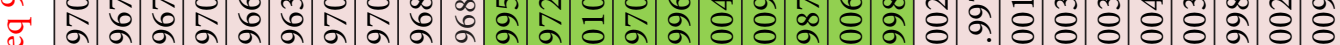

$\exists$ ปิ

$\infty$ மூர்

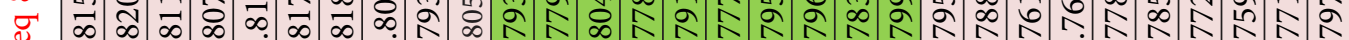

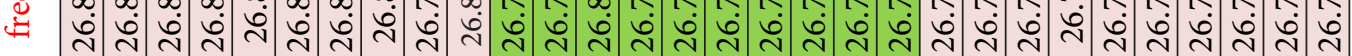

n

ન 귀

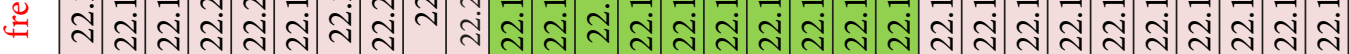

6

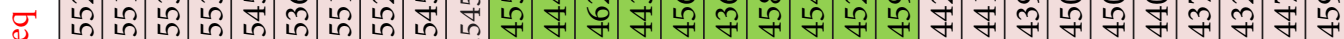

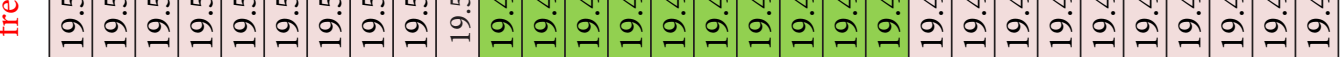

n

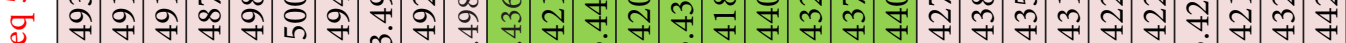

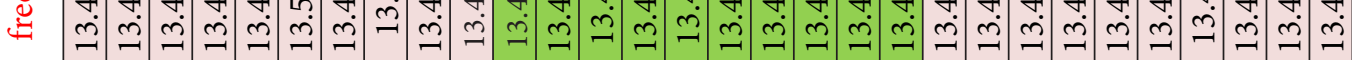

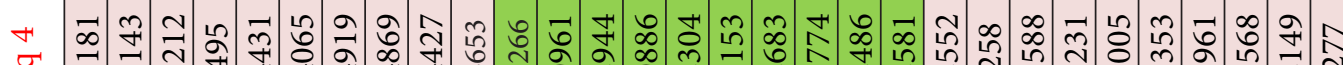

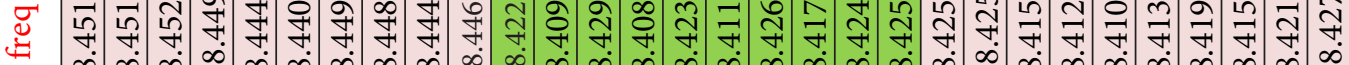

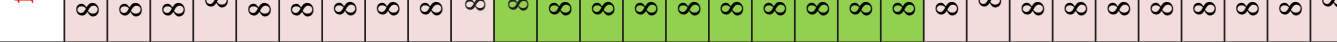

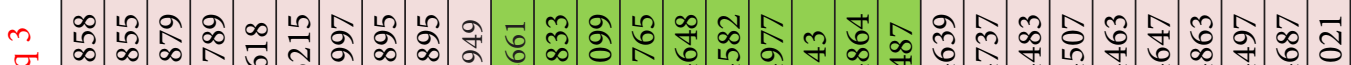

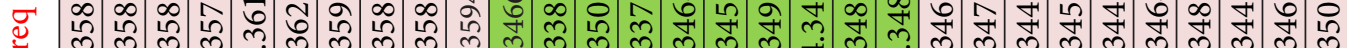

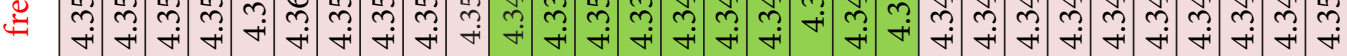

v సี

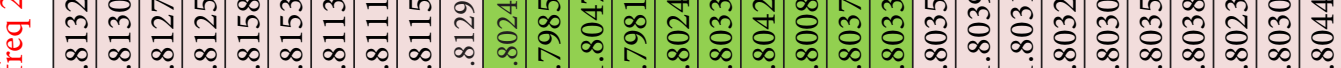

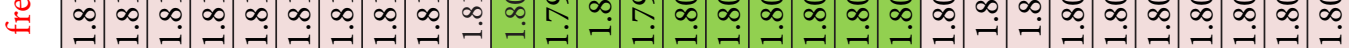

-

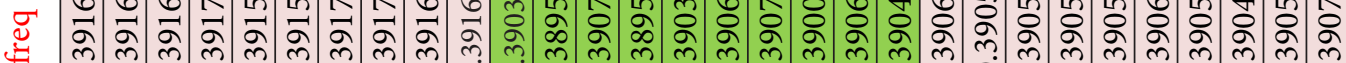

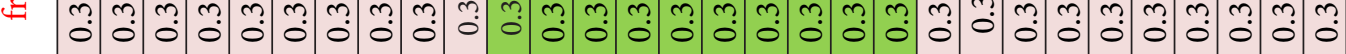

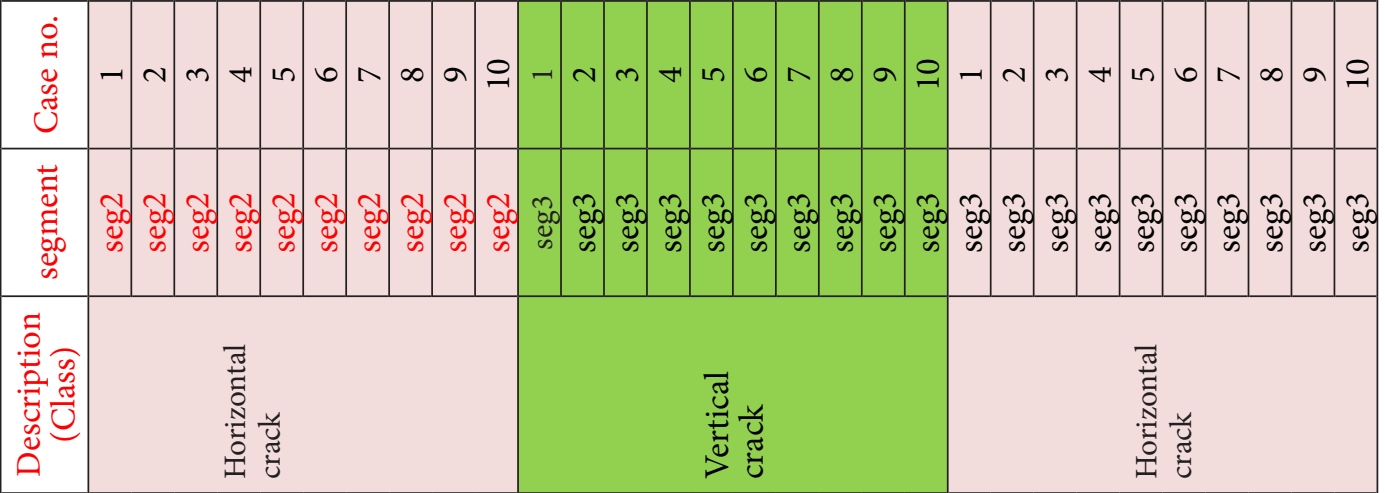

